\title{
Gentrificación en España y América Latina. Un diálogo crítico ${ }^{1}$
}

\author{
Michael Janoschka², Jorge Sequera ${ }^{3}$ y Luis Salinas ${ }^{4}$
}

\begin{abstract}
RESUMEN
Las principales transformaciones sociales y políticas, así como la implementación de las políticas urbanas neoliberales han alterado profundamente la estructuración de las ciudades en España y América Latina. Entre sus consecuencias destaca la reconquista de los centros urbanos por las clases acomodadas, que conlleva la expulsión de los hogares con menores ingresos, un fenómeno generalmente abordado mediante el término de gentrificación. Hasta el momento y en comparación con la abundante literatura anglosajona sobre gentrificación, pocos investigadores han prestado atención al fenómeno en estas dos áreas geográficas. Este artículo responde a esta laguna y ofrece una exhaustiva revisión de los debates sobre gentrificación que se han producido en España y América Latina durante la última década, siguiendo dos presupuestos. En primer lugar, se hace hincapié en la necesidad de caracterizar los discursos de la gentrificación en España y América Latina, para conseguir una adecuada apropiación y contextualización del concepto. $Y$ en segundo lugar, se afirma que la gentrificación en España y América Latina difiere sustancialmente de los procesos observados en el mundo anglosajón. A partir de este análisis se propone por tanto una reconsideración y repolitización del concepto de gentrificación a través de la visión territorial y lingüística de los investigadores españoles y latinoamericanos.
\end{abstract}

Palabras clave: Gentrificación, neoliberalismo, revanchismo, resistencia.

\begin{abstract}
Major social and political transformations such as the shift towards neoliberal urban policies have widely altered the contemporary structuring of metropolitan areas in Spain and Latin America. One key consequence is the recapture of city centres by wealthy tenants and the eviction of poorer households, a phenomenon usually designated by the term gentrification. In comparison to the comprehensive documentation of gentrification in the Anglophone environment, few scholars
\end{abstract}

\footnotetext{
Este texto es la traducción del artículo "Gentrification in Spain and Latin America - a Critical Dialo-

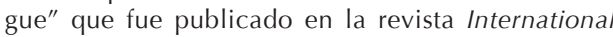
Journal of Urban and Regional Research, 2014, Vol. 38, № 4, p. 1234-1265 (DOI:10.1111/14682427.12030). Agradecemos a la editorial Wiley la cesión de los derechos de autor. La investigación fue apoyada por el Séptimo Programa Marco de la Comisión Europea (FP7-PEOPLE-PIRSESGA-2012-318944, 2012-2016). Además, recibió apoyo de la Universidad Autónoma de Madrid y el Banco Santander. Los autores también agradecen el apoyo del Ministerio de España de Ciencia e Innovación (MICINN: RYC-2010-06177 y BES-2008008.944) y la Dirección General de Estudios de
}

Posgrado de la Universidad Nacional Autónoma de México. Damos las gracias a Rodrigo Hidalgo, Patricia Olivera y Ramón Espinar y a tres evaluadores de la revista IJURR (International Journal of Urban and Regional Research) por sus útiles comentarios sobre versiones anteriores de este manuscrito.

2 Departamento de Ciencia Política y Relaciones Internationales, Universidad Autónoma de Madrid (España).E-mail: michael.janoschka@uam.es

3 Departamento de Ciencia Política y Relaciones Internationales, Universidad Autónoma de Madrid (España). E-mail: jorge.sequera@uam.es

4 Departamento de Ciencia Política y Relaciones Internationales, Universidad Autónoma de Madrid (España). E-mail: luis_arreortua@hotmail.com 


\begin{abstract}
have paid attention to this phenomenon in this area of the world so far. This article responds to this gap, providing an exhaustive revision of the debates about gentrification occurring in Spain and Latin America during the last decade and tracking two theoretical motivations. First, it stresses the necessity of characterizing gentrification discourses in Spain and Latin America, preparing a conceptual appropriation and contextualization of the term itself. Second, it confirms that gentrification in Spain and Latin America varies substantially from processes observed in the Anglophone world. As a result, the review develops insights into emancipating and challenging debates that remain useful for the mainstream gentrification discourse too. Addressing this, it proposes a reconsideration and repoliticization of gentrification through the territorial and linguistic lens of Spanish and Latin American researchers.
\end{abstract}

Key words: Gentrification, neoliberalism, revanchism, resistance.

\begin{abstract}
Algunas evidencias sugieren que tanto las expresiones simbólicas y materiales de la gentrificación en España y América Latina, como los discursos científicos al respecto difieren marcadamente de aquellos que tienen lugar en el mundo anglosajón. A partir de esta premisa, el siguiente análisis desarroIlará, desde una perspectiva holística, una visión común sobre la investigación de la gentrificación en las ciudades españolas y latinoamericanas. Al mismo tiempo, se mantendrá un diálogo con las demandas teóricas que sostienen que las 'geografías de la gentrificación' de las ciudades fuera del mundo anglosajón requieren unas exploraciones sustanciales y estudios comparativistas innovadores (Lees, 2012). Para ello, se presenta una revisión exhaustiva de la literatura sobre los discursos de gentrificación en (y sobre) España y América Latina, que reúna los debates en inglés, español y portugués. Nuestro objetivo consiste no solo en abordar una novedosa línea de investigación. Se desarrolla además un marco analítico científica y políticamente coherente para entender mejor la gentrificación desde una perspectiva 'latina'. Esto implica por tanto reconsiderar la gentrificación a través de la visión territorial y sociolingüística de los investigadores españoles y latinoamericanos, articulando diálogos entre ellos y el discurso anglófono convencional. Para tal fin, abordamos la gentrificación contemporánea como una expresión fundamental y un resultado clave de las políticas urbanas neoliberales y del revanchismo urbano, procesos que han sido ampliamente reconocidos en ambas áreas geográficas (Janoschka, 2002; Swyngedouw et al., 2002; Portes \& Roberts, 2005; López \& Rodríguez, 2011). Adicionalmente, se verán reforzados los enfoques emancipatorios en la producción de
\end{abstract}

un conocimiento postcolonial y el carácter distintivo de la gentrificación fuera del núcleo anglófono (Maloutas, 2011). Por lo tanto, el artículo hace referencia a comparaciones que "trascienden la división global entre el Norte y el Sur" mediante "explicaciones matizadas, complejas y contextualizadas" de las realidades y los procesos urbanos (Robinson, 2011: 18). En este sentido, se aportará evidencia de cómo los investigadores españoles y latinoamericanos incorporan perspectivas nuevas, emancipadoras y desafiantes que contribuyen a descentrar los enfoques teóricos de la gentrificación contemporánea. Sin embargo, cabe señalar que el artículo propone más que una descripción del estado de la cuestión. Así, mediante las innovaciones y las resignificaciones desarrolladas, se reforzarán algunas demandas como las que fueron expresadas por Tom Slater (2006), para desarrollar una teoría urbana crítica que reflexiona a través de la gentrificación contra la gentrificación. Pero antes comenzaremos por algunas consideraciones acerca de los contextos institucionales e intelectuales para la generación del conocimiento científico en España y América Latina, que ayudarán a comprender la propuesta de investigación integral y holística de los procesos de gentrificación que se propone en este artículo.

\section{Gentrificación en España y América Latina. Una introducción a contextos de producción científica descentrada}

Reunir las discusiones de España y América Latina sobre la gentrificación en una 
propuesta holística requiere algunas matizaciones, debido especialmente a que una parte importante de los debates en los estudios urbanos españoles y latinoamericanos (y en la investigación de la gentrificación) están intrínsecamente relacionados a los discursos existentes del mundo anglosajón. Sin embargo, esto es solamente una cara de la moneda. Una especificidad esencial de los debates de gentrificación en el mundo 'latino' se relaciona con cuestiones epistemológicas más amplias o, en otras palabras, con la posición desde la cual la gentrificación es considerada. Así, una diferencia clave consiste en la sólida tradición que tienen los estudios sobre los movimientos sociales urbanos en España y América Latina, que generan narraciones, contextos y redes compartidos entre los investigadores sociales críticos. En este sentido, los primeros trabajos de Manuel Castells (1973, 1974 [1972]; 1974), centrados en las transformaciones conflictivas del espacio urbano desde una perspectiva marxista, establecen ya algunas pautas para la esencia de la investigación urbana emancipadora realizada posteriormente. Asimismo, muchos investigadores mantienen un intenso diálogo con la obra de teóricos franceses como Bourdieu, Foucault y Lefebvre. Esto se basa en el hecho de que, en décadas anteriores, muchos investigadores marxistas se escaparon de la persecución de las dictaduras en el sur de Europa y América Latina, marchándose al exilio. En aquellos momentos, se encontraron con un ambiente extraordinariamente inspirador en las universidades francesas. En consecuencia, por citar solo un ejemplo, el debate de la obra filosófica de Lefebvre sobre la producción del espacio y el derecho a la ciudad comenzó tan pronto como se publicaron sus libros, precediendo su recepción posterior en los estudios urbanos en el mundo anglosajón. Tal incorporación histórica, lingüística y geográfica crea trayectorias que son anteriores a los debates actuales sobre la gentrificación, estimulando una incorporación y un uso selectivo de ciertos términos.

Algo similar justifica las estrechas relaciones que muchos investigadores urbanos mantienen con las demandas vecinales, por ejemplo cuando desarrollan su trabajo desde una posición que fusiona el activismo con la investigación, originando enfoques intrínsecamente críticos o a veces una implicación activa. Desde ya muchas décadas algunos autores como Milton Santos, Boaventura de Sousa Santos o Raúl Zibechi han ido madurando propuestas contrahegemónicas que explícitamente acentúan perspectivas teóricas arraigadas en sus respectivos idiomas. En este sentido, cualquier curso de postgrado en estudios urbanos críticos en España y América Latina varía definitivamente de la (re)producción del conocimiento canónico que se efectúa en el mundo anglosajón. Esto se debe en parte a la forma en que el conocimiento está incrustado en los respectivos idiomas, pero igualmente resulta de las lógicas epistemológicas en la producción del conocimiento científico. Por ejemplo, la posición social de muchos científicos en España y América Latina difiere marcadamente de sus homólogos del mundo anglosajón, especialmente si tenemos en cuenta las condiciones laborales precarias de los jóvenes investigadores. Como consecuencia, no son rápidamente absorbidos dentro del estatus social distintivo que los investigadores adquieren en otras partes del mundo y que crea fácilmente una "ignorancia epistémica nacida del privilegio que la nobleza académica disfruta" (Allen, 2008: 181). Esta ausencia de un estatus social y económico típico de clase media con sus respectivos privilegios implica una distancia menor entre lo observado y el observador. En muchos casos, los investigadores urbanos participan activamente en luchas contra los planes exclusivistas de renovación, generando una fuerte empatía con el entorno en el que la investigación se lleva a cabo. Aunque la situación de aquellos que son defendidos por los movimientos sociales suele ser peor que la de los investigadores, se trata a la vez de una relación cercana y reconocible. Tal investigación etnográfica exige la práctica de la reflexividad, por lo que una "expulsión de las perspectivas críticas" (Slater, 2006) apenas existe. Hasta el momento, solo algunos investigadores de la Pontificia Universidad Católica de Santiago de Chile han abordado el término desde perspectivas que apuntan a neutralizar la investigación crítica sobre gentrificación (Sabatini et al., 2008; Contreras, 2011). Al contrario, en los demás casos el término gentrificación permite a los científicos de habla hispana y portuguesa afinar y desarrollar enfoques críticos sobre las políticas urbanas, ausentes en los discursos predominantes sobre los procesos de gobernanza ur- 
bana, revitalización y renovación (Janoschka, 2011).

Partiendo de lo anterior, también es de vital importancia reconocer que la región lingüística de España y América Latina proporciona unas estructuraciones políticas, económicas, sociales y administrativas específicas que influyen en la implementación del neoliberalismo urbano, así como en el ensamblaje de la gentrificación como una de sus expresiones locales. Siguiendo los argumentos de Borsdorf e Hidalgo (2010), las políticas neoliberales han producido durante las últimas dos décadas un determinado 'modelo' de desarrollo urbano en América Latina. El modelo describe la creciente fragmentación y privatización del ámbito urbano a través de la implementación de una ideología revanchista, cuyo objetivo es reconquistar los centros de las ciudades para las clases acomodadas (Bromley \& Mackie, 2009; Crossa, 2009). Asimismo, los modos de gobernanza neoliberal que han sido introducidos y aplicados en áreas urbanas españolas aportan evidencias de que una forma muy específica de acumulación de capital ha emergido en el marco de un modelo urbano más amplio de aplicación de políticas neoliberales (López \& Rodríguez, 2011; Naredo y Montiel, 2011). Por consiguiente, es posible afirmar que las políticas del empresarialismo urbano, así como otras estrategias en el ámbito social y político que tienen el fin de promover la gentrificación, están condicionadas en ambas regiones por trayectorias comunes. Esto significa también que muchas de las decisiones políticas y profesionales se fundan en estructuraciones urbanas que hasta cierto grado son comparables entre sí. Existen múltiples semejanzas, tales como un proceso tardío de suburbanización, la decadencia previa de las áreas centrales urbanas y la reciente implementación de ambiciosos programas de renovación mediante esquemas de partenariado público-privado (Walliser \& Bruquetas, 2004; Janoschka \& Borsdorf, 2006). Además, las ciudades de España y América Latina han desarrollado igualmente unas redes profesionales compartidas mediante canales profundamente entrelazados, lo que recientemente se ha definido desde debates académicos como la 'movilidad de las políticas' (policy mobility: Cook, 2008; Evans, 2009; McCann, 2011). Los técnicos y administrativos muni- cipales, así como políticos, investigadores de consultoras privadas, profesores y estudiantes universitarios cultivan redes educativas y profesionales que fomentan y refuerzan la movilidad transatlántica de las políticas urbanas. Por ejemplo, González (2011) pone en evidencia el papel crucial que los 'exitosos' procesos de revitalización de Barcelona y Bilbao jugaron para estas policy mobilities. Otro caso de las políticas originadas en España que posteriormente entreverados se aplicaron en muchas ciudades de América Latina es la 'planificación estratégica' para el desarrollo urbano. Carlos Vainer (2011) ilustra esto, comparando la implementación de los planes estratégicos en Barcelona y Río de Janeiro, así como los regímenes de excepcionalidad asociados a la celebración de los respectivos Juegos Olímpicos. Igualmente, es bien conocido que algunos urbanistas catalanes eran importantes actores en proyectos de renovación urbana como la regeneración del paseo fluvial en Guayaquil (Ecuador, proyecto Malecón 2000) y de Puerto Madero en Buenos Aires. Implementados desde la década de los 1990 bajo el predominio de las filosofías neoliberales dominantes de la época, son dos ejemplos de gentrificación liderada por el Estado que fracasaron claramente por no cumplir las promesas iniciales de mezcla social y de provisión de infraestructura pública (Cuenya y Corral, 2011).

Todas estas similitudes incluyen la idea de que tanto en España como en América Latina no solo se experimentó un retraso temporal en la aparición de la gentrificación; inicialmente también los investigadores erraron en reconocer y adaptar el concepto a los diferentes contextos sociales, políticos y urbanos en los que estaba ocurriendo. Hasta cierto punto, esto responde a agendas y modas científicas más amplias. Por ejemplo, en España los Juegos Olímpicos de 1992 proporcionaron un impulso importante para el seguimiento y la 'venta' de la 'historia exitosa' de la regeneración de Barcelona (Monclus, 2003; Marshall, 2004), un modelo que hoy en día se aborda críticamente (Degen \& García, 2012). Asimismo, a finales de 1990, los debates se centraban en el 'efecto Guggenheim' (Gómez, 1998; Plaza, 1999; Gómez \& González, 2001), mientras a principios de 2000 eran las altas tasas de inmigración (Arbaci, 2007; Pareja-Eastaway, 2009; Portes et 
al., 2010) y las consecuencias perjudiciales del boom inmobiliario (López \& Rodríguez, 2010). Estos debates hegemónicos relegaron la investigación de la gentrificación en España a un lugar secundario. En América Latina, algo similar estaba sucediendo. El comienzo del nuevo siglo fue testigo de amplios debates sobre el aumento de la exclusión social que estaba ocurriendo después de la proliferación de las urbanizaciones cerradas, íntimamente relacionados con una crisis urbana producida de forma discursiva, centrándose en la inseguridad y la delincuencia (Caldeira, 2000; Janoschka \& Borsdorf, 2006; Giglia, 2008; Roitman \& Phelps, 2011; Salcedo \& Torres, 2004).

\section{Gentrificación en España y América Latina. Una revisión crítica}

Aunque la proliferación global de la gentrificación fue reconocida reiteradamente en la última década (Smith, 2002; Atkinson \& Bridge, 2005; Lees et al., 2008; Porter \& Shaw, 2008), todavía son poco frecuentes los estudios empíricos tanto sobre las ciudades en el 'Sur Global' anglófono (Ghertner 2011; Harris 2008; Visser \& Kotze 2008) como en otros entornos culturales (Ergun, 2004; Fujitsuka, 2005; Islam, 2005; Lutzeler, 2008; He, 2010). En comparación con la documentación exhaustiva y crítica en las ciudades norteamericanas y británicas, pocos investigadores han prestado atención a la gentrificación en otras regiones del mundo y esto es particularmente nítido en las ciudades de América Latina y España. Esta brecha se suele asociar a diferentes temporalidades de los procesos de gentrificación. Por ejemplo, hace poco más de 15 años, Jones \& Bromley (1996: 375) defendieron en un análisis de las políticas de conservación y renovación urbana en las ciudades latinoamericanas que "la evidencia disponible sugiere que la conservación no es una condición suficiente para producir paisajes urbanos gentrificados". En términos similares, Ward (1993) y Ford (1996) habían declarado en ese momento que se esperaba que los centros urbanos de América Latina continuaran perdiendo los residentes acomodados hacia áreas suburbanas. Una situación similar se hizo evidente en España, donde los núcleos urbanos sufrieron continuas pérdidas de población hasta mediados o finales de 1990 debido a la expansión suburbana (Muñoz, 2003; Catalán et al., 2008). Solo recientemente, es decir, durante la primera década del siglo XXI, se ha empezado a enfocar la gentrificación. Este hecho convierte la siguiente revisión bibliográfica en una herramienta esencial para estructurar los discursos emergentes sobre la gentrificación en el mundo 'latino'.

\section{Consideraciones metodológicas}

Esta revisión bibliográfica sobre la gentrificación en las ciudades de España y América Latina tiene en cuenta publicaciones en inglés, español y portugués ${ }^{5}$. Se basa en una búsqueda exhaustiva en revistas arbitradas en idioma inglés, sobre todo aquellas que aparecen en las bases de datos 'Thomson-Reuters $\mathrm{SSCl}^{\prime}$ y 'Scopus-SciVerse'. Para considerar la literatura en español y portugués, se utilizaron los dos principales motores de búsqueda de España e Iberoamérica: Dialnet ${ }^{6}$ y Redalyc $^{7}$. Como estas bases de datos poseen conocidas deficiencias con respecto a debates que tienen lugar en otro tipo de publicaciones que son cruciales en las Ciencias Sociales, se llevó a cabo una búsqueda adicional de monografías, capítulos de libro, tesis doctorales, ponencias en congresos y otras publicaciones en la web. Con el objetivo de analizar solamente investigaciones genuinas sobre procesos de gentrificación, se aplicaron dos criterios adicionales de selección. En primer lugar, fueron considerados todos los documentos que simultáneamente hacen uso del término "gentrificación" y se refieren a por lo menos una ciudad latinoamericana o española. Des-

\footnotetext{
5 La literatura en francés y alemán, así como en idiomas no mayoritarios de la Península Ibérica fueron igualmente detectadas, pero no se tomarán en cuenta en este análisis.

6 Dialnet es una base de datos científica desarrollada y actualizada por la Universidad de La Rioja (Logroño) y la Fundación Dialnet. Colabora con 69 bibliotecas científicas en España y cinco países de América Latina y registra el contenido de 907 revistas en Ciencias Sociales. Disponible en Internet: http:// dialnet.unirioja.es /

7 Redalyc es una plataforma alojada en la Universidad Autónoma del Estado de México, que ofrece acceso abierto a 758 revistas científicas publicadas en español y portugués, 534 de ellos en el campo de las Ciencias Sociales. Disponible en Internet: http:// redalyc.uaemex.mx/
} 
pués, todos los artículos sin marco conceptual sustancial acerca de la gentrificación fueron excluidos. Finalmente, se identificaron 39 publicaciones en inglés, 19 de las cuales aluden a ciudades de América Latina y 20 a áreas urbanas de ciudades españolas. Además, fueron analizados 45 textos que se refieren a casos de estudio de ciudades españolas y 41 documentos que hablan de la gentrificación en ciudades de América Latina.

\section{Gentrificación en España y América}

Latina. Características de un campo de investigación emergente

En primer lugar, es preciso constatar el carácter emergente de los debates de gentrificación en España y América Latina. No obstante, incluyen una asombrosa variedad de entornos urbanos latinoamericanos; desde las megaciudades como la Ciudad de México, São Paulo y Río de Janeiro, pasando por las capitales nacionales (Santiago de Chile, Quito, Montevideo y La Habana), ciudades medianas de provincia (Puebla, Cuenca, Cusco, Recife, Salvador de Bahía) hasta localidades más pequeñas como Guanajuato (México) o Trinidad (Cuba). Sin embargo, el debate de gentrificación se sigue produciendo al margen de las corrientes principales en los estudios urbanos latinoamericanos, que prefieren aplicar términos como renovación urbana, revitalización, rehabilitación y otros neologismos para referise a las estrategias de transformación urbana supuestamente 'exitosas' (Díaz Orueta et al., 2003; Botelho, 2005; Riviere, 2006; Aguirre y Marchant, 2007). Además, parte del debate sobre la gentrificación en las ciudades de América Latina está aún dominado por perspectivas anglófonas, financiadas y publicadas especialmente por investigadores provenientes del 'Norte Global'. Como consecuencia de ello, varios estudios latinoamericanos esquivan el término gentrificación por representar un "concepto anglosajón" (Jaramillo, 2006: 20), tratando de proponer adaptaciones semánticas no siempre satisfactorias como "ennoblecimiento" (enobrecimento en portugués: Bortolozzi, 2009; Leite, 2010), o perfilar la gentrificación a través del problemático término de "elitización" (González-Hernández, 2009).

Esta situación es algo diferente con respecto a España, donde el discurso internacio- nal confluyó ágilmente con las contribuciones científicas españolas en un marco común. Muchos autores españoles han (co)publicado en revistas y libros en inglés, y las publicaciones en ambos idiomas se sitúan a menudo en discursos y debates teóricos similares. Al margen de algunas aclaraciones iniciales y revisiones teóricas necesarias para introducir un término novedoso en otro idioma (Vázquez, 1992, 1996; Sargatal, 2000; Martínez, 2001; Rodríguez et al., 2001), el estudio de la neoliberalización urbana se aplica en casi todas las ciudades españolas más importantes de forma regular a través del concepto de la gentrificación. Los autores han puesto poca resistencia a familiarizarse con el término (García, 2001), y son conscientes de las ventajas que tiene para perfilar mejor las dimensiones polémicas del fenómeno. La mayoría de los textos no cuestiona la aplicación del concepto en un contexto social y urbano diferente (Duque, 2010a). Este pragmatismo también incluye el desarrollo de investigaciones holísticas sobre la gentrificación, como en el estudio del municipio de Madrid, a través de diferentes tipos de datos estadísticos, así como de una crítica a los planes públicos de renovación y regeneración urbana (Muñoz, 2009). Otro ejemplo podría ser el estudio de Díaz Parra (2009), quien reúne diferentes líneas de investigación sobre la gentrificación, como los clásicos enfoques de producción y de consumo, con el objetivo de desarrollar una teoría general de gentrificación y renovación urbana.

En resumen, nuestra caracterización preliminar muestra evidencias de cómo los extendidos efectos de la renovación urbana parecen ser utilizados, tanto en España como en América Latina, como sinónimos de la gentrificación en la ciudad contemporánea. Esta noción ha alcanzado una madurez suficiente para presentarse conceptualmente coherente para explicar las reestructuraciones sociales y espaciales en la ciudad neoliberal. Por ende, parece evidente que toda sustitución del pasado por algo nuevo se implementa ahora mediante mecanismos gentrificadores. Esta idea difiere claramente de algunas de las ramas de la investigación tradicional sobre gentrificación, especialmente de las nociones que arraigan el concepto a las primeras manifestaciones del fenómeno que fueron discutidas por Ruth Glass (1964) en Londres, en un 
momento en que el Estado de Bienestar keynesiano estaba en su apogeo y el neoliberalismo era un término inexistente. Sin embargo, como veremos a continuación, para España y América Latina, la gentrificación debería ser abordada a través de un punto de vista que contemple la diversidad de matices y las espacialidades conflictivas del neoliberalismo urbano (Brenner et al., 2010a).

\section{Gentrificación en España. Debates y discursos}

A pesar de su ubicación teórica en el seno de la literatura anglófona, la investigación empírica de la gentrificación en España introduce importantes variaciones del discurso convencional anglosajón, caracterizados por seis perspectivas de interés. En el Cuadro $\mathrm{N}^{\circ}$ 1 se proporciona una visión general de estas dimensiones que contribuye a seguir desarrollando la caracterización que aquí se propone, entre otras cosas, se atiende a los principales autores y las ciudades en las que los procesos han sido observados. Además, esa figura ayuda el reconocimiento de un debate que abarca mucho más que los dos ejemplos emblemáticos de Barcelona y Bilbao que han estado dominando la representación internacional de los procesos de gentrificación en España en los últimos años.

1. Gentrificación y migración transnacional: Durante la década anterior a la crisis financiera y económica, la expansión de la economía española, conectada con los procesos de globalización, atrajo más de 5 millones de inmigrantes hacia el país; así, España fue el destino europeo más importante para los flujos de

Cuadro $\mathrm{N}^{\circ} 1$

Gentrificación en España. Perspectivas y debates

\begin{tabular}{|c|c|c|}
\hline Tipo y Descripción & Ciudades & Autores \\
\hline $\begin{array}{l}\text { Gentrificación y migración } \\
\text { trasnacional }\end{array}$ & Madrid, Barcelona, Bilbao & $\begin{array}{l}\text { Arbaci, 2008; Arbaci \& Malheiros, 2010; } \\
\text { Ávila \& Malo, 2008; Barañano et al., 2006; } \\
\text { Cavia et al., 2008; García, 2003; Martínez } \\
\text { \& Leal, 2008; Pérez-Agote et al., 2010; Riol, } \\
\text { 2003; Sargatal, 2001, 2003, 2009; Suárez, } \\
\text { 2009; Tabakman, 2001 }\end{array}$ \\
\hline $\begin{array}{l}\text { Gentrificación turística } \\
\text { (impulsada por el Estado) }\end{array}$ & $\begin{array}{l}\text { Palma de Mallorca, Santa } \\
\text { Cruz de Tenerife, Valencia, } \\
\text { Bilbao }\end{array}$ & $\begin{array}{l}\text { Franquesa, 2007; García, 2003; García et al., } \\
\text { 2007; Morell, 2009; Prytherch \& Boira, 2009; } \\
\text { Romero \& Trudelle, 2011; Vicario \& Martínez, } \\
\text { 2003, 2005; Vives, } 2011\end{array}$ \\
\hline $\begin{array}{l}\text { Gentrificación productiva y } \\
\text { comercial }\end{array}$ & $\begin{array}{l}\text { Barcelona, Bilbao, Madrid, } \\
\text { Valencia, Sevilla }\end{array}$ & $\begin{array}{l}\text { Boixader, 2004; Díaz Parra, 2008, 2010; Dot } \\
\text { et al., 2010; Guillamón, 2003; Justo, 2011; } \\
\text { Ribera-Fumaz, 2008; Santamarina, } 2009\end{array}$ \\
\hline $\begin{array}{l}\text { Gentrificación simbólica y } \\
\text { producción cultural }\end{array}$ & Madrid, Bilbao, Barcelona & $\begin{array}{l}\text { Cañedo, 2006; Delgado, 2008; Díaz Orueta, } \\
\text { 2007; Fraser, 2007; Rodríguez \& Vicario, } \\
\text { 2005; Sequera, } 2010\end{array}$ \\
\hline $\begin{array}{l}\text { Nuevas geografías de la } \\
\text { gentrificación: } \\
\text { - gentrificación provincial } \\
\text { - gentrificación rural }\end{array}$ & $\begin{array}{l}\text { Granada, León, áreas } \\
\text { rurales en Cataluña }\end{array}$ & $\begin{array}{l}\text { Bouzarovski et al., 2010; Buzar et al., 2007; } \\
\text { Cánoves \& Blanco, 2006; Duque, 2010b; } \\
\text { Haase, 2008; Moreh, 2011; Solana, 2006, } \\
\text { 2008, } 2010\end{array}$ \\
\hline $\begin{array}{l}\text { Resistencia a la } \\
\text { gentrificación }\end{array}$ & $\begin{array}{l}\text { Madrid, Valencia, Sevilla, } \\
\text { Granada, Vigo }\end{array}$ & $\begin{array}{l}\text { Díaz Orueta, 2007; Díaz Parra, 2008; Gómez, } \\
\text { 2006; Martínez, 2011; Moreh, 2011; Morell, } \\
\text { 2009; Prytherch \& Boira, 2009; Ramos et al., } \\
\text { 2008; Romero \& Trudelle, } 2011\end{array}$ \\
\hline
\end{tabular}

Fuente: Elaboración propia. 
la migración transnacional. Muchos de los inmigrantes se asentaron en áreas centrales que simultáneamente estaban sujetas a procesos de renovación y gentrificación. Estos vínculos entre gentrificación y migración han sido abordados desde una perspectiva comparativa de diferentes ciudades del sur de Europa (Arbaci \& Malheiros, 2010), introduciendo la interesante cuestión de la coexistencia de ambos mecanismos en las ciudades españolas. Basado en investigaciones empíricas, Arbaci (2008: 595-596) muestra la discontinuidad de la gentrificación, como un proceso que no ha trascendido a barrios enteros, los centros históricos representan todavía espacios no homogéneos de revalorización y territorios fragmentados bajo continua reapropiación. Al contrastar dos calles adyacentes en Barcelona, Sargatal (2001) sostiene que los programas públicos de renovación estimulan la gentrificación, pero en coexistencia con la inmigración, un signo de mercados inmobiliarios espacialmente segmentados. Diferentes estudios en Madrid (Barañano et al., 2006; Ávila y Malo, 2008; Martínez y Leal, 2008; Pérez-Agote et al., 2010) y Bilbao (Cavia et al., 2008; Suárez, 2009) muestran que los inmigrantes económicos sufren exclusión residencial y segregación espacial. Pero en ambas ciudades no existe evidencia de un desplazamiento importante por la persistente gentrificación de los barrios correspondientes. La situación parece ser diferente en Barcelona, donde la renovación del Casc Antic, especialmente del barrio del Raval, está relacionado con políticas públicas que fomentan la 'higienización social' en las áreas con alta concentración de inmigrantes (Tabakman, 2001; Sargatal, 2003; 2009), especialmente de origen paquistaní (García, 2003; Riol, 2003).

2. Gentrificación turística (impulsada por el Estado): Como uno de los destinos turísticos más importantes del mundo, España ha realizado importantes esfuerzos para reajustar su modelo de turismo de masas basado en 'playa y sol', una actividad con bajas tasas de ganancia, hacia un turismo urbano inspirado en la puesta en valor del patrimonio histórico y cultural.
Al respecto, es interesante ver cómo las lógicas de apropiación espacial por las actividades turísticas implican la proliferación de procesos de gentrificación. Al contrario del carácter de laissez-faire en la mayoría de las políticas públicas, los políticos locales y regionales mostraron una decidida voluntad de allanar el terreno para fomentar la gentrificación turística (García et al., 2007: 277). Esta interrelación es el sujeto de diferentes análisis: entre otros, Romero y Trudelle (2011) han estudiado cómo los megaproyectos urbanos han producido gentrificación en los tradicionales barrios obreros de Valencia desde mediados de la década de 1990. Desde una perspectiva diferente, Prytherch \& Boira (2009) advierten de la inauguración de más de 20 salas de exposiciones y museos de propiedad pública en la misma ciudad en tan solo una década, una abrumadora expansión de las actividades económicas, relacionadas con la preparación simbólica de la ciudad como un espacio para los turistas. Además, como ocurrió en Bilbao La Vieja (Vicario \& Martínez, 2003, 2005) y en los barrios de Grau y Natzaret en Valencia (Romero \& Trudelle, 2011), la gentrificación turística impulsada por el Estado ha integrado también los espacios residenciales semiperiféricos en los circuitos de valorización económica. Y en otras ciudades como Palma de Mallorca y Santa Cruz de Tenerife, el desplazamiento por el turismo está siendo acelerado aún más por la inversión de los fondos de la UE y las políticas implementadas por el programa URBAN (García et al., 2007; Morell, 2009). Finalmente, se considera también el papel que desempeñan los turistas no solo como consumidores del entorno urbano, sino como actores del mercado inmobiliario y compradores de segundas residencias y de apartamentos vacacionales (García, 2003).

3. La gentrificación productiva y comercial: Barcelona y en cierta medida Bilbao han sido pioneros en la elaboración y aplicación de políticas que se esfuerzan por reconvertir antiguas áreas industriales, por ejemplo en la zona de la Ría de Bilbao, el área portuaria de Barcelona y el barrio de Poble Nou, renombrado Bar- 
celona 22@. Una de las consecuencias de la aplicación de las ambiciosas estrategias de renovación es que los antiguos espacios industriales y barrios de clase trabajadora han sido reapropiados por la economía de servicios y del conocimiento, tanto en términos de uso residencial como productivo (Guillamón, 2003; Boixader, 2004). Estos estudios coinciden en recordar las a menudo agresivas estrategias de marketing empleadas para transformar la imagen de la ciudad. En este sentido, Dot et al. (2010) proponen introducir diferentes perspectivas de análisis a los estudios de la gentrificación, es decir, investigar principalmente el sector empresarial y las compañías que se establecen en un barrio en proceso de transformación. Sugiriendo la etiqueta de gentrificación productiva, apoyan un enfoque hacia la reconfiguración espacial derivada de nuevas actividades económicas, relacionándolo con los discursos que tratan de atraer a los integrantes de la clase creativa para vivir y trabajar en determinados barrios. Como las administraciones locales promueven activamente la renovación urbana, la gentrificación productiva resultante puede ser considerada otra expresión de la gentrificación impulsada por el Estado. En términos similares, Santamarina (2009) analiza el barrio del Cabanyal en Valencia como un espacio social amenazado por los megaproyectos propuestos por el sector público. O Justo (2011), que indica cómo un barrio céntrico de Madrid en decadencia (ahora renombrado Triball) fue el objetivo de una empresa inmobiliaria para impulsar la revalorización al establecer una 'marca comercial' como parte de un plan para atraer a diseñadores de moda, así como fomentar un determinado tipo de comercio mediante subvenciones concedidas por el propio inversor privado. Este enfoque reúne las perspectivas de la gentrificación productiva y la gentrificación comercial (Ribera-Fumaz, 2008), a través de la construcción de un barrio como un producto específico, como barrio marca. Siendo partícipe de este debate, Díaz Parra (2008, 2010) observó cómo las transformaciones en la composición social en Sevilla, incluyendo el desplazamiento de los grupos de ingresos más bajos, son provocadas tanto por la gentrificación productiva como por la gentrificación comercial.

4. Gentrificación simbólica vía producción cultural institucionalizada: Autores como Sequera (2010) han discutido las consecuencias de la renovación urbana a largo plazo, desde una perspectiva que la interpreta como una expresión y como parte de las múltiples prácticas biopolíticas que implementan determinados modelos de conducta y civilidad neoliberal. Haciendo referencia al barrio de Lavapiés en el centro histórico de Madrid, señala la introducción de nuevos estilos de vida basados en prácticas de consumo y modelos de ciudadanía distintivas a partir de la proliferación de nuevas infraestructuras culturales y de espacios comerciales. Delgado (2008) denomina este efecto como 'artistización', un proceso implementado por políticas públicas que abarcan la reapropiación empresarial y consumista de unos centros urbanos que son transformados en parques temáticos y espacios mercantilizados. Esta gentrificación simbólica del espacio público mediante la instauración de infraestructuras para la producción cultural institucionalizada es una cuestión clave para interpretar la dialéctica entre lo público y lo privado como una de las múltiples expresiones de la naturaleza especulativa del capital en la ciudad contemporánea (Fraser, 2007: 677). Aduciendo argumentos teóricos de Harvey y Lefebvre, Fraser critica la creciente exclusión de los espacios públicos de personas no deseadas, como parte de la preparación de espacios urbanos asépticos. Mediante el estudio de las políticas de vigilancia en el Parque del Retiro en el centro de Madrid, muestra cómo la gentrificación simbólica del espacio público forma parte de una dominación más amplia de la esfera pública, guiada por los intereses de los actores privados que tienen por objetivo la gentrificación generalizada del espacio urbano. Siguiendo esta línea y a partir de los debates surgidos de Bilbao, cabe señalar que la retórica de la ciudad creativa es otro tema clave, leitmotiv de la renovación urbana. Las políticas públicas respondieron 
al paradigma de la ciudad creativa de Richard Florida, tratando de establecer un entorno favorable para la atracción de empresarios culturales. Rodríguez y Vicario (2005) presentan una coherente crítica a esta lógica, afirmando que el marketing urbano solamente reviste las evidentes estrategias de gentrificación, mientras que desplaza los problemas urbanos en lugar de resolverlos. Tomando el barrio de Lavapiés en Madrid como ejemplo de una investigación exhaustiva sobre el cambio social contemporáneo, Pérez-Agote et al. (2010) entienden la producción cultural como un mecanismo principal de la gentrificación. Ellos reflexionan sobre las intervenciones de la administración pública en la promoción de las actividades culturales para fomentar identidades nuevas, artificiales y pretenciosas, de un Lavapiés imaginado como elegante y en boga. Más allá de su centralidad geográfica, este barrio posee una rica mezcla cultural y social que lo transforma en un entorno 'exótico' en el que los ámbitos alternativos y artísticos se reafirman como representaciones culturales globalizadas. En este sentido, Díaz Orueta (2007) afirma que este barrio cosmopolita de ubicación céntrica se puede comprender como un laboratorio de nuevos estilos de vida basadas simultáneamente en representaciones bohemias e identidades de izquierda (Cañedo, 2006). Los discursos de muchos de estos jóvenes profesionales incluyen tanto una relación instrumental con el vecindario, que se basa en su centralidad, la producción cultural y la oferta de actividades de ocio, como una reificación de y una fuerte identificación con las luchas contrahegemónicas, anticapitalistas, de activismo político y de participación activa en la propia producción de la vida cultural (Barañano et al., 2006).

5. Las nuevas geografías de la gentrificación: Los debates actuales distinguen la existencia de "gentrificación provincial" en España, tomando en cuenta investigaciones sobre Granada (Duque, 2010b; Moreh, 2011) y un estudio comparativo realizado en la ciudad castellana de León y otras urbes medianas de cuatro países europeos (Buzar et al., 2007;
Haase, 2008; Bouzarovski et al., 2010). Por su parte, Solana (2006, 2008 y 2010) analiza la movilidad de la población en Cataluña y ofrece una visión sustancial del conjunto de la transformación en la composición social que se produce en zonas rurales, alegando que se está definitivamente generando una gentrificación rural. Además, otras perspectivas enfatizan en la organización posfordista del trabajo que permite la relocalización de actividades productivas en las zonas rurales, fomentando la sustitución progresiva de la población local por los recién llegados con mayores ingresos (Cánoves \& Blanco, 2006).

6. La resistencia a la gentrificación: Como se mencionó anteriormente con respecto al trabajo pionero de Manuel Castells (1974 [1972]; 1974; 1983), cabe destacar que los estudios de los movimientos sociales y de la resistencia a la implementación del urbanismo neoliberal son hoy día una característica prominente en los estudios urbanos españoles. En este sentido, no sorprende que las consecuencias negativas que los vecinos y otros protagonistas sufren en las áreas en proceso de gentrificación se presenten como una prioridad en la investigación social. Por ejemplo, la resistencia local ha sido analizada en Madrid (Díaz Orueta, 2007), Valencia (Prytherch \& Boira, 2009; Romero \& Trudelle 2011), Granada (Moreh, 2011) y Vigo (Martínez, 2011). Esa línea de investigación es prominente en las ciudades que desde hace tiempo están siendo dominadas por políticas conservadoras, como Madrid y Valencia, y que además cuentan con estrategias institucionales de participación ciudadana poco innovadoras. En esta tradición, Díaz Parra (2008) investigó las estrategias de contestación producidas por las asociaciones de vecinos cuando reivindican vivienda pública y defienden a los habitantes de los barrios en proceso de gentrificación. Además, analiza posibles respuestas y propuestas para detener, o al menos interponerse a la gentrificación contemporánea. En la contribución de Ramos et al. (2008), se retrata el caso de Granada para reflejar el papel activo y potente que los investigadores sociales 
pueden desempeñar para organizar, apoyar y reorientar estas luchas a través de la investigación participativa y la intervención social, un aspecto que ha ganado un mayor relieve desde que se produjo la movilización de los indignados españoles en mayo de 2011, con la ocupación y liberación de edificios vacíos que ha tenido lugar desde entonces en diferentes barrios que están siendo atravesados por los procesos de gentrificación (Abellán et al., 2012).

Como conclusión preliminar es posible destacar que esta revisión ayuda a entender que la investigación de la gentrificación en y sobre las ciudades españolas puede caracterizarse como un campo altamente combativo y crítico. El uso del término de gentrificación está incrustado dentro de una amplia crítica al modelo urbano neoliberal y sus consecuencias sociales y espaciales, como la segregación, el clasismo, las desigualdades y el desplazamiento.

Gentrificación en América Latina. Debates y discursos

El discurso sobre la gentrificación en las ciudades latinoamericanas se introdujo por primera vez por Jones \& Varley (1999), quienes analizaron los procesos de conservación en el centro colonial de Puebla (México). De acuerdo con los argumentos de Neil Smith (1996) sobre la ciudad revanchista, afirman que la gentrificación constituye la "reconquista simbólica de un espacio sobre el cual las clases medias locales habían perdido la autoridad moral" (Jones \& Varley, 1999: 1547). Esta cita demuestra que los debates sobre la gentrificación en América Latina aportan ciertos matices para pensar la creciente diversidad de la gentrificación a nivel mundial. Por lo tanto, es de vital importancia referirse a las condiciones materiales y simbólicas de la transformación urbana desde el comienzo del experimento neoliberal. Y con el fin de caracterizar y estructurar la bibliografía existente, se han elaborado cuatro dimensiones que están mutuamente entrelazadas (Cuadro No 2).

En términos cuantitativos, los estudios más importantes sobre la gentrificación en América Latina consisten en el análisis de las diferentes formas de "gentrificación simbólica" que se relacionan frecuentemente con las políticas que reescenifican y ponen en valor el extraordinario patrimonio arquitectónico de los centros históricos latinoameri-

Cuadro $\mathrm{N}^{\circ} 2$

Gentrificación en América Latina. Perspectivas y debates

\begin{tabular}{|c|c|c|}
\hline Tipo y Descripción & Ciudades & Autores \\
\hline $\begin{array}{l}\text { Gentrificación simbólica: } \\
\text { - racial, étnica } \\
\text { - gentrificación turística, patri- } \\
\text { monial } \\
\text { - migración por ocio, turismo } \\
\text { residencial } \\
\text { - mecanismos de control, zonas } \\
\text { especiales de 'rescate' }\end{array}$ & $\begin{array}{l}\text { Buenos Aires, Ciudad } \\
\text { de México, Quito, Sal- } \\
\text { vador de Bahía, Recife, } \\
\text { Fortaleza, Vitória, San } \\
\text { Luis, Tiradentes, São } \\
\text { Thomé das Letras, La } \\
\text { Habana, Cuenca, Boca } \\
\text { del Toro }\end{array}$ & $\begin{array}{l}\text { Bailey (2008); Bélanger (2008); Botelho } \\
\text { (2005); Bromley \& Mackie (2009); Checa- } \\
\text { Artasu (2011); Crossa (2009); Donovan } \\
\text { (2008); Frúgoli \& Sklair (2008); Herzer } \\
\text { (2008); Hiernaux (2006); Jackiewicz \& } \\
\text { Crane (2010); Jones \& Varley (1999); Leite } \\
\text { (2010); Middleton (2003); Monterrubio } \\
\text { (2009); Nelle (2009); Nobre (2002); Porte- } \\
\text { la (2009); Scarpaci (2000); Steel \& Klaufus } \\
\text { (2010); Swanson (2007); Walker (2008); } \\
\text { Zolini (2007) }\end{array}$ \\
\hline $\begin{array}{l}\text { Políticas neoliberales de gentri- } \\
\text { ficación: } \\
\text { - gentrificación turística } \\
\text { - gentrificación impulsada por } \\
\text { el Estado } \\
\text { - revitalización y gentrificación }\end{array}$ & $\begin{array}{l}\text { Santiago de Chile, Ciu- } \\
\text { dad de México, Río de } \\
\text { Janeiro, São Paulo, Re- } \\
\text { cife, Salvador }\end{array}$ & $\begin{array}{l}\text { Crossa (2009); Frúgoli \& Sklair (2008); } \\
\text { Hiernaux (2006); Inzulza-Contardo } \\
\text { (2012); Rivière (2006); Rubino (2005); } \\
\text { Walker (2008) }\end{array}$ \\
\hline
\end{tabular}


Continuación Cuadro $N^{\circ} 2$

\begin{tabular}{|c|c|c|}
\hline Tipo y Descripción & Ciudades & Autores \\
\hline $\begin{array}{l}\text { Nuevos mercados inmobiliarios } \\
\text { y gentrificación: } \\
\text { - gentrificación de barrios po- } \\
\text { pulares en sitios periféricos y } \\
\text { centrales }\end{array}$ & $\begin{array}{l}\text { Montevideo, Porto Ale- } \\
\text { gre, Río de Janeiro, Sal- } \\
\text { vador da Bahía, Santia- } \\
\text { go de Chile }\end{array}$ & $\begin{array}{l}\text { Álvarez-Rivadulla (2007); Carrión } \\
\text { (2005); Cavalcanti (2009); Checa-Artasu } \\
\text { (2011); Del Río (2004); Gaffney (2010); } \\
\text { Gonçalves (2011); Goulart (2005); Hidal- } \\
\text { go (2010); Ivo (2012); Lima (2010); Ló- } \\
\text { pez-Morales (2010, 2011); Nery \& Moura } \\
\text { de Castilho (2008); Sanfelici (2010) }\end{array}$ \\
\hline $\begin{array}{l}\text { Resistencia a la gentrificación: } \\
\text { - movimientos sociales contra- } \\
\text { hegemónicos } \\
\text { - de-gentrificación }\end{array}$ & $\begin{array}{l}\text { São Paulo, Río de Janei- } \\
\text { ro, Buenos Aires, San- } \\
\text { tiago de Chile, Córdoba }\end{array}$ & $\begin{array}{l}\text { Bidou-Zachariasen (2006); Casgrain \& } \\
\text { Janoschka (2013); Delgadillo (2009, } \\
\text { 2012); Hernández-Medina (2010); Her- } \\
\text { zer (2008); Leite (2010); Mandrini et al. } \\
\text { (2010); Menezes \& Monteiro (2010); } \\
\text { Monteiro \& de Andrade (2012); Monte- } \\
\text { rrubio (2009); Oliveira \& Gaffney (2010); } \\
\text { Rolnik (2011); Sanfelici (2007) }\end{array}$ \\
\hline
\end{tabular}

Fuente: Elaboración propia.

canos. Por ello, varios autores valoran esta estrategia como un mero pretexto para atraer nuevamente a las élites locales y a las clases medias acomodadas a los centros históricos (Hiernaux, 2006; Belanger, 2008). Como Botelho (2005) demuestra, esto puede suceder mediante una superposición de procesos tradicionales de gentrificación impulsados por promotores inmobiliarios, así como por una gentrificación simbólica basada en el comercio y el consumo. En muchos casos, la implementación de los correspondientes programas de intervención y gobernanza se despliega en cooperación con la Organización de las Ciudades del Patrimonio Mundial de la UNESCO.

Jones y Varley (1994, 1999) argumentan que en las ciudades latinoamericanas los "vendedores ambulantes" encarnarían una importante molestia para los posibles gentrificadores, dado que muchos de ellos son de una composición racial y étnica diferente de las clases medias y media altas, así como de la mayoría de los turistas extranjeros y "blancos". Más allá de eso, Scarpaci (2000: 289) afirma que en La Habana, los gentrificadores son "un grupo transitorio compuesto por turistas extranjeros o empresarios de Canadá, Europa occidental y América Latina". Su argumento fue reafirmado posteriormente por Bailey (2008), mientras que Steel y Klaufus (2010) mostraron evidencias empíricas de que la gentrificación en Cuenca (Ecuador) ha sido originada por la llegada de norteamericanos jubilados. Este tipo de movilidad y migración entre los EE.UU. y Canadá y los destinos latinoamericanos, motivada por cuestiones de ocio y estilo de vida, implica frecuentemente una serie de conflictos en relación a la apropiación del espacio urbano que se articulan a través de los debates sobre el derecho a la ciudad (Jackiewicz \& Crane, 2010; Garriz, 2011). Siguiendo este argumento, Prado (2012) denomina la migración relativamente privilegiada de norteamericanos y europeos a los destinos costeros y los centros históricos de las ciudades latinoamericanas como "gentrificación global". Este proceso se relaciona intrínsecamente con las estrategias de inversión transnacional, y la movilidad residencial transfronteriza relacionada con el ocio, implicando el desplazamiento conflictivo de los habitantes locales (Janoschka, 2009).

Volviendo a la cuestión de la reescenificación del patrimonio urbano y su papel clave en la gentrificación simbólica, es importante señalar que el nexo entre el comercio informal y las nuevas políticas públicas está presente en todas las contribuciones a este asunto (Middleton, 2003; Swanson, 2007; Donovan, 2008 Bromley \& Mackie, 2009; Crossa, 2009). Aunque aplican diferentes marcos teóricos, los autores mencionados coin- 
ciden en que la expulsión de los vendedores ambulantes prepara los centros históricos y otros paisajes urbanos simbólicamente para la gentrificación. Esto va unido a los resultados obtenidos por investigadores latinoamericanos que han analizado casos como la restauración del centro colonial de Salvador de Bahía y de Recife (Nobre, 2002; Portela, 2009; Leite, 2010), o de los espacios turísticos de La Boca y de San Telmo en la zona sur de la ciudad de Buenos Aires (Herzer, 2008). Como señalan otros autores, la preparación de los centros históricos latinoamericanos para su gentrificación simbólica destruye algunos de los elementos que mayor encanto poseen, conduciendo a una "musealización" del Patrimonio Mundial (Monterrubio, 2009; Nelle, 2009). Además, la supuesta 'limpieza' de las zonas urbanas del comercio informal, así como de los indigentes y toxicómanos (Frugoli \& Sklair, 2008) intenta doblegar unas tradiciones duraderas de apropiación comercial de la esfera pública urbana (Bromley \& Mackie, 2009; Crossa, 2009). Los comerciantes de clases populares son desplazados de las calles de los centros urbanos con el fin de potenciar el creciente negocio turístico y así, el centro es 'rescatado', como proponen los Ilamados "Programas de Rescate" en diferentes ciudades mexicanas (Cabrales, 2005; Crossa, 2009). La implementación de estos programas está íntimamente relacionada con la transferencia de paradigmas políticos de los EE.UU. hacia América Latina, especialmente cuando se trata de la aplicación de las políticas securitarias y de medidas relacionadas con el control y la higiene, la imitación de las políticas de tolerancia cero o la aplicación de la videovigilancia del espacio público (Walker, 2008).

Con el fin de profundizar en la comprensión de los mecanismos de gentrificación en América Latina, es de gran importancia discutir el papel clave que desempeña la administración pública para establecer los mecanismos normativos que se establecen en las ciudades para la gentrificación (simbólica). Estas perspectivas han sido ampliamente abordadas en la investigación de la gentrificación en América Latina, por ejemplo, mediante el análisis de los mecanismos por los que las "políticas neoliberales de gentrificación" son aplicadas y adoptadas en unos entornos sociales, políticos y administrativos y urbanos que históricamente no habían de- sarrollado un Estado de Bienestar keynesiano. El ejemplo más Ilamativo de estas coaliciones tácitas entre inversores y autoridades públicas parece ser actualmente Santiago de Chile, dando lugar a una reorganización altamente fragmentada de las áreas centrales, con la reciente construcción de condominios de gran altura (Inzulza-Contardo, 2012). Hidalgo (2010) va un paso más allá y refleja la influencia crucial que tienen las universidades privadas como actores clave de la configuración neoliberal y en la transformación y gentrificación de algunos barrios centrales en Santiago de Chile. Otra idea innovadora de la 'ciudad empresarial neoliberal' (Crossa, 2009) es la recogida por la tesis doctoral inédita de Walker (2008). Este autor reconoce que el "Programa de Rescate" en la Ciudad de México no es otra cosa que la neoliberalización planificada del espacio, en una ciudad mucho más desigual que cualquiera de los países del "Norte Global", aplicado para 'gestionar' las capas humildes de la sociedad. A fin de orquestar la gentrificación del centro histórico de la Ciudad de México, la herencia más grande y simbólicamente más importante de la arquitectura colonial y pre colonial en el continente americano, se lleva a cabo una coalición inaudita entre un gobierno local de pseudoizquierda y la Fundación del magnate Carlos Slim, considerado el hombre más rico del mundo. Para mejorar la atracción y recolonización de los centros urbanos mediante la implantación de viviendas de lujo, nuevos conjuntos residenciales surgen detrás de las fachadas de los edificios coloniales o del siglo XIX, algo que se está experimentando de forma similar en las mayores ciudades brasileñas como Río de Janeiro, São Paulo, Recife y Salvador (Rubino, 2005; Frugoli \& Sklair, 2008). Sin embargo, en el caso de la Ciudad de México, la "normalización" de la calle lograda por la disciplina, el castigo y la eliminación de los vendedores ambulantes puede considerarse como prototípico. El aspecto innovador consiste en que la gentrificación aquí forma parte de la dominación de un magnate cuyos intereses son principalmente de carácter económico, aunque han sido bien articulados a partir de discursos románticos acerca de la recuperación de un imaginario urbano anclado en un pasado lejano.

Esto nos conduce al siguiente aspecto, que figura como una condición previa para la 
gentrificación en muchas ciudades de América Latina y que consiste en las importantes reconfiguraciones en el rol social, político y económico de la vivienda y especialmente en la "producción de nuevos mercados inmobiliarios". Entre otras, las áreas centrales han sido blanco de los desarrolladores nacionales y los fondos transnacionales de inversión que explotan las enormes brechas de renta que resultaron del constante y largo abandono. Haciendo referencia al ejemplo de Porto Alegre, Sanfelici (2010) reconoce los profundos nexos entre los programas de desarrollo inmobiliario y un sector financiero cada vez más poderoso. En términos similares, LópezMorales $(2010,2011)$ aplica el modelo de rent-gap (Smith, 1987) para explicar la situación en las áreas semiperifericas en Santiago de Chile. Analiza algunos instrumentos específicos de planificación neoliberal así como la liberalización de las normativas de la construcción, que proporcionaron las bases de una creciente acumulación de la renta de suelo capitalizada por un pequeño grupo de empresas inmobiliarias y promotores, a expensas de los pequeños propietarios de los terrenos que han sido sistemáticamente desposeídos. Por cierto, no es casualidad que este tipo de debates se hayan presentado principalmente en Chile y Brasil, los dos países latinoamericanos que tienen la mayor desigualdad en la distribución de la riqueza (Kaztmann \& Ribeiro, 2008; Hidalgo y Arenas, 2011).

Otro aspecto de la función que los mercados inmobiliarios de reciente creación tienen para incentivar la gentrificación está relacionado con la 'pacificación' de los asentamientos informales en la ciudad, que previamente fueron estigmatizados. En las ciudades brasileñas, estas políticas se implementan mediante un permanente "estado de excepción" (Vainer, 2000) que aprovecha los discursos sobre la "ciudad del miedo" o la "fobópolis" (en portugués, fobópole; Lopes de Souza, 2008). Esto significa que durante la continuada consolidación de las favelas y de otros asentamientos informales, los mercados inmobiliarios se expanden a nuevas partes de la ciudad, transformando ampliamente las condiciones de vida de sus habitantes (Cavalcanti, 2009; Gonçalves, 2011). En el caso de Río de Janeiro, esto es especialmente importante, ya que se basa en programas como el denominado "Favela-Bairro", con cuyos fondos se produjo en las últimas dos décadas una importante inversión para fomentar la 'regeneración' de estos barrios de autoconstrucción (Perlman, 2010). Debido a la inminente gentrificación de algunas de las favelas ubicadas en áreas centrales o en las proximidades de las playas y la zona costera, destinos principales para un futuro despliegue del mercado inmobiliario formal, esta ciudad presenta actualmente un escenario altamente contestatario. Estas tendencias se aceleran además por las transformaciones provocadas por los próximos megaeventos como la copa del mundo de la FIFA en 2014 y los Juegos Olímpicos. Como analizan Gaffney (2010) y Lima (2010), la historia de la planificación urbana en Río de Janeiro anticiparía que los avances en democracia implementados por las diferentes agendas de reforma urbana, los presupuestos participativos y otros instrumentos otorgados por el Estatuto de la Ciudad en Brasil, podrían retroceder como resultado de la implementación de los regímenes de excepción, así como de la hegemonía de las llamadas "coaliciones de crecimiento" (Rolnik, 2011; Hernández-Medina, 2010). Esta situación es similar en otras ciudades que utilizaron estrategias de intervención urbana como modelo para la generación de nuevos mercados inmobiliarios. Así, incluso en las "Zonas especiais de Interesse Social" (ZEIS), cuando se aplican regulaciones urbanas no elitistas, la expulsión y la gentrificación han sido reportadas como efectos secundarios, como en São Paulo u otras ciudades brasileñas (Del Río, 2004; Goulart, 2005; Nery \& Moura de Castilho, 2008; Irazabal, 2009; Ivo, 2012).

Un proceso similar se está produciendo en algunas áreas centrales, especialmente en las que los posibles aumentos de alquiler eran hasta el momento fuertemente regulados, por lo menos hasta el final de modelo económico basado en la sustitución de importaciones. La consiguiente protección de los inquilinos tenía como efecto secundario el crecimiento de las brechas de renta que ahora, en condiciones de economías de mercado e insertados en la globalización, han sido extraídos en gran medida (para la Ciudad de México, véase Checa-Artasu, 2011). Además, la gentrificación de las áreas céntricas está igualmente relacionada con la rápida 
mercantilización de la vivienda de interés social mediante los mecanismos del mercado. A pesar de que debiera dar solución a la cuestión de la vivienda, la producción contemporánea de la vivienda social elimina de manera implícita los hogares de menores recursos del centro de la ciudad. Este es especialmente el caso de Santiago de Chile, dado que las subvenciones concedidas son tan bajas que solo la vivienda pública desarrollada en áreas periféricas cumple con los requisitos formales para esta población (Hidalgo, 2010). Como consecuencia, los residentes con menor poder adquisitivo son estratégicamente expulsados de las áreas centrales de la ciudad (Carrión, 2005).

Otro enfoque interesante para reunir a las geografías de la fragmentación, privatización y la proliferación de barrios cerrados con el discurso de la gentrificación ha sido desarroIlado por Álvarez-Rivadulla (2007). Ella nos recuerda que la proliferación de los barrios cerrados en lugares suburbanos ha sido responsable de gran parte de la expansión urbana desde principios de 1990. Es importante destacar que la suburbanización en América Latina no tiene lugar en un paisaje deshabitado, sino que especialmente los límites suburbanos han sido lugares tradicionales para los asentamientos de los hogares más humildes. En consecuencia, están dominados por viviendas informales y de autoconstrucción de bajo coste que habitualmente carecen de plena tenencia legal (Gilbert, 1994; Crowley, 1998; Davis, 2006). Sin embargo, las mejoras de las infraestructuras, como la construcción de carreteras eficaces han revalorizado la mayoría de las periferias urbanas latinoamericanas (Janoschka \& Borsdorf, 2006), y esto pone en peligro a los barrios marginales mediante el aumento de desalojos y desplazamientos. Basado en un estudio sobre la proliferación de urbanizaciones cerradas en Montevideo, Álvarez-Rivadulla (2007) identifica las significativas trayectorias de clase de nuevos habitantes para conceptualizar la suburbanización como una nueva forma de gentrificación, un enfoque prometedor para estudios en diferentes ciudades. Resumiendo, este y los tres mecanismos que se discutieron aquí, diferentes pero mutuamente entrelazados, maduran una de las posibles explicaciones de cómo, en América Latina, la creación de nuevos mercados inmobiliarios está intrínse- camente vinculada con la producción de la ciudad gentrificada.

Finalmente, es importante resaltar los debates relacionados con la "resistencia a la gentrificación" y con las posibilidades de desarrollar luchas contrahegemónicas bajo las actuales condiciones de desenfrenada acumulación capitalista. Por ejemplo, diferentes investigadores establecen vínculos entre el movimiento por el derecho a la ciudad y la gentrificación, interpretada esta como una descripción de los efectos negativos del capitalismo global en los barrios centrales (Mandrini et al., 2010). Este discurso es especialmente potente entre los investigadores brasileños. Basándose en David Harvey, Henri Lefebvre y Milton Santos, Sanfelici (2007) propone estrategias para repolitizar las luchas de los movimientos sociales urbanos. Esto se relaciona con la cuestión planteada por Casgrain y Janoschka (2013) donde, en Santiago de Chile, los movimientos sociales urbanos se refieren explícitamente al término de "gentrificación". Tales articulaciones ayudan a establecer alianzas entre investigadores e inquilinos de áreas centrales y semiperiféricas que temen el desplazamiento debido a la continua reestructuración urbana. De este modo, diferentes debates se refieren a los conflictos ocultos de los planes de renovación urbana que están relacionados con los próximos megaeventos en Río de Janeiro (Oliveira \& Gaffney, 2010; Monteiro \& De Andrade, 2012). Por otro lado, Delgadillo (2009), análiza la contestación a las políticas excluyentes y exclusivas que están relacionadas con el turismo urbano, deconstruyendo la finalidad de las políticas de control que han sido abordado anteriormente. Leite (2010) va un paso más allá y reconoce que la reapropiación de la ciudad por los movimientos sociales podría revertir el proceso de gentrificación a través de lo que denomina "antinobrecimiento", un término que podría traducirse como contragentrificación o degentrificación. Dichas sugerencias recuerdan que las actuales corrientes políticas de izquierda y centro-izquierda podrían ralentizar la gentrificación en América Latina a través de nuevos enfoques y experimentos populares (Irazabal, 2009). En este sentido, la investigación de la gentrificación en América Latina se nutre de algunos de los experimentos políticos llevados a cabo desde principios del siglo XXI, que colocan 
la defensa, la reconstrucción de los bienes públicos y el desarrollo de nuevos modelos de inclusión social, como cuestiones clave en las políticas urbanas, limitando algunos de los efectos adversos del neoliberalismo urbano (Roberts, 2005; Hernández-Medina, 2010; Rolnik, 2011). Sin embargo, la experiencia de Brasil nos recuerda al mismo tiempo que todas las luchas en contra de los mecanismos del mercado tienen que comenzar con una reconfiguración del campo semántico del urbanismo, ya que conceptos tales como revitalización, que se han convertido en un significante general para los procesos de gentrificación en América Latina, están profundamente arraigados en un conjunto de discursos económicos, sociales y simbólicos que necesitan ser alterados (Bidou-Zachariasen, 2006). En este sentido, la investigación que se preocupa por la resistencia a la gentrificación y la reivindicación del derecho a la ciudad tiene que desafiar los discursos hegemónicos que esconden la gentrificación tras una cortina de humo discursiva (Sanfelici, 2007; Menezes \& Monteiro, 2010; Delgadillo, 2012).

\section{Los discursos convencionales de gentrificación y el estudio de la gentrificación en España y América Latina, un diálogo crítico}

El siguiente análisis de los discursos de la gentrificación en España y América Latina integrará el discurso anglosajón convencional con el fin de desarrollar una perspectiva comparativista. Para ello, se tomarán en consideración en primer lugar las tres diferencias clave entre España y América Latina, siendo la más importante la cuestión del desplazamiento. Por ejemplo, la gran mayoría de los estudios realizados en España no se centran explícitamente en la expulsión de los residentes, sino que estudian las diferentes facetas de la postmodernidad, las condiciones de vida de los inmigrantes y el mercado inmobiliario dual en los barrios en proceso de gentrificación. En cambio, los casos latinoamericanos recuerdan que la limpieza social y la depuración de los barrios con hogares de menores ingresos o el desalojo de vendedores ambulantes pueden considerarse elementos constitutivos de la gentrificación y del revanchismo urbano. Esto no significa que la ideología revanchista esté ausente en España, pero definitivamente está interpretada bajo diferentes formas de actuación. Conceptos tales como raza, etnicidad y clase tienen significados claramente distintos en España, donde el Estado de Bienestar existente configura además la vida urbana de una manera diferente. Esto conduce al segundo punto; concretamente, que los lugares donde se está produciendo la gentrificación difieren. Mientras la gentrificación en España sucede principalmente en los barrios céntricos y semiperiféricos de la ciudad (con la excepción de la gentrificación rural), por el contrario, en las ciudades de América Latina también se someten a la gentrificación algunas áreas suburbanas, por ejemplo a través de las urbanizaciones cerradas que tienden a desplazar a la población más desfavorecida. Además, el papel que juega el patrimonio arquitectónico en la gentrificación es de alguna manera diferente en ambas regiones. En las ciudades españolas, la renovación del patrimonio es una parte de las estrategias impulsadas por el Estado, de embellecimiento, musealización y turistificación de los centros históricos, así como un activo para atraer a los trabajadores del conocimiento. Sin embargo, en América Latina, las administraciones locales dan mayores concesiones a los inversores que transforman el patrimonio arquitectónico en centros comerciales y otros recreativos y de ocio altamente comercializados. Todo esto muestra que se aplican algunas lógicas diferentes en la preparación simbólica de la ciudad para su gentrificación.

A pesar de ello, la revisión comparativa de la gentrificación a través de la visión territorial y lingüística de España y América Latina también proporciona similitudes significativas que ilustran una imagen coherente. Por ejemplo, los regímenes políticos transnacionales (como la red europea URBAN o las políticas de protección del patrimonio de la UNESCO) juegan un papel importante para establecer las bases fundamentales de la gentrificación, un aspecto que evidencia cómo los "sistemas de transferencia política interjurisdiccional" (Brenner et al., 2010b) ayudan a difundir las políticas neoliberales de gentrificación. Además, la gentrificación relacionada con el turismo puede ser considerada como uno de los principales ejes de investigación en el mundo latino. Esto responde al impor- 
tante rol que juega el turismo en muchas economías urbanas en España y América Latina, y también la capacidad transformadora que ha alcanzado en las economías basadas en los servicios. En otras palabras, el turismo puede ser considerado el fundamento que apunta a la transformación simbólica del espacio urbano a través de estrategias de gentrificación impulsadas por el Estado. Esto nos lleva de nuevo a observar que las coaliciones generalizadas entre políticos y actores económicos se integran en los discursos de la economía de mercado que de manera persistente allanan el camino para la implementación de las políticas neoliberales de gentrificación. Además, el estudio comparativo de la gentrificación en España y América Latina también nos permite observar mejor la gentrificación simbólica en el capitalismo contemporáneo. Aunque las formas y los códigos puedan variar considerablemente de una ciudad a otra, la implementación de las políticas neoliberales habitualmente restringe las posibilidades de apropiación del espacio para la reproducción social y económica de las poblaciones excluidas y con escasos recursos.

Esto se relaciona con la perspectiva crítica implícita de los investigadores españoles y latinoamericanos en los debates sobre gentrificación, que concentran esfuerzos considerables en analizar la resistencia a la gentrificación. Como se mencionó anteriormente, dicho compromiso es parte de la reflexividad de los investigadores, partidarios de aquellos que tradicionalmente son excluidos de los "beneficios" del urbanismo neoliberal y de otro tipo de políticas públicas exclusivas, como los sectores no conformistas de la sociedad, de las clases subrepresentadas. Los estudios sobre resistencia a la gentrificación no solo amplían el potencial transformador de la investigación participativa, sino también permiten el desarrollo de nuevas posiciones y de enfoques emancipadores capaces de propagarse a los discursos principales de la investigación urbana. A continuación, esta caracterización será abordada y aclarada mediante el estudio de la relación entre los discursos convencionales del mundo anglófono y los de España y América Latina. Como se expresa de manera sintética en el Cuadro $N^{0} 3$, los principales discursos sobre gentrificación en el mundo anglosajón son muy diferentes a los establecidos en el mundo "latino". En este sentido, cinco escenarios diferentes caracterizan la mutua interrelación, así como las diferencias y las brechas existentes entre la investigación sobre la gentrificación en España y América Latina y la del mundo anglosajón.

La primera situación descrita se refiere a los debates acerca de las "políticas neoliberales de gentrificación", que reconocen el papel fundamental que desempeña el Estado en impulsar los procesos de gentrificación (Hackworth, 2002; Smith, 2002; Lees, 2008), un aspecto que también se discute bajo el título de gentrificación "impulsada por el Estado" o

Cuadro $\mathrm{N}^{\circ} 3$

Perspectivas comparativas sobre los discursos de gentrificación en España, América Latina y los discursos anglófonos convencionales

\begin{tabular}{|l|l|}
\hline $\begin{array}{l}\text { Caracterización de los debates de } \\
\text { gentrificación }\end{array}$ & \multicolumn{1}{c|}{ Contenidos y discursos } \\
\hline $\begin{array}{l}\text { Discurso anglófono convencional, así } \\
\text { como en España y América Latina } \\
\text { (debates fuertes y similares en todas las } \\
\text { áreas geográficas) }\end{array}$ & $\begin{array}{l}\text { - Políticas neoliberales de gentrificación } \\
\text { Solo en el discurso anglófono conven- } \\
\begin{array}{l}\text { cional } \\
\text { (debates inexistentes o insignificantes en impulsada por el Estado }\end{array} \\
\begin{array}{l}\text { España y América Latina) } \\
\text { - Supergentrificación (geografías de la gentrificación en } \\
\text { ciudades globales) }\end{array} \\
\begin{array}{l}\text { Políticas neoliberales de mezcla social y gentrificación } \\
\text { Gentrificación de nueva construcción }\end{array} \\
\text { - Nuevas geografías de la gentrificación (gentrificación } \\
\text { provincial, gentrificación rural) }\end{array}$ \\
\hline
\end{tabular}


Continuación Cuadro $N^{\circ} 3$

\begin{tabular}{|c|c|}
\hline $\begin{array}{l}\text { Caracterización de los debates de } \\
\text { gentrificación }\end{array}$ & Contenidos y discursos \\
\hline $\begin{array}{l}\text { Predominantemente en España } \\
\text { (debates claves en España y debates dé- } \\
\text { biles/escasos en el discurso anglófono } \\
\text { convencional y en América Latina) }\end{array}$ & - Gentrificación y flujos de migración trasnacional \\
\hline $\begin{array}{l}\text { Predominantemente en América Latina } \\
\text { (debates claves en América Latina y } \\
\text { debates débiles/escasos en el discurso } \\
\text { anglófono convencional y en España) }\end{array}$ & - Nuevos mercados inmobiliarios y gentrificación \\
\hline $\begin{array}{l}\text { Predominantemente en España y Améri- } \\
\text { ca Latina } \\
\text { (debates claves en España y América } \\
\text { Latina y debates débiles/escasos en el } \\
\text { discurso anglófono convencional) }\end{array}$ & $\begin{array}{l}\text { - Gentrificación simbólica (gentrificación turística, gentrifi- } \\
\text { cación de comercio minorista, gentrificación productiva) } \\
\text { - Resistencia a la gentrificación }\end{array}$ \\
\hline
\end{tabular}

Fuente: Elaboración propia.

"basada en las políticas públicas" (Davidson, 2008; Rousseau, 2009). Estas políticas, desplegadas por las diferentes Administraciones Públicas, se pueden considerar como pauta habitual, como parte de una activa implementación de políticas neoliberales de gentrificación y como un medio para requerir la ciudad para los negocios, la clase media y las fuerzas del mercado en general (Peck, 2006: 681). Tales políticas públicas se ejemplifican en los partenariados público-privados como los destinados a la regeneración de las zonas portuarias (Butler, 2007; Doucet et al., 2011a; 2011 b), la recuperación de antiguas zonas industriales (Díaz Orueta y Fainstein, 2009), o la renovación de los centros históricos para satisfacer las demandas de los consumidores de clase media y alta (Zukin, 1998). En todos estos casos, el Estado no solo organiza activamente la desposesión de los hogares de menores ingresos, sino que también implementa una poderosa estrategia discursiva para ocultar cualquier interpretación de su propia acción como parte de una agresiva ideología revanchista, diseñada para reconquistar el centro de la ciudad para las clases medias (Lees, 2008). Si bien estas disposiciones pueden considerarse una regla general del desarrollo urbano reciente, los ejemplos de España y América Latina introducen nuevos conocimientos sobre las geografías variadas de la gentrificación.
Pero a partir de este momento, los puntos comunes entre el mundo "latino" y el discurso convencional de la gentrificación finalizan, y a lo largo de las cuatro categorías restantes podemos establecer algunas distinciones esenciales. Por ejemplo, algunos de los debates intensos del discurso anglófono no tienen ninguna o solamente una muy reducida equivalencia en España y América Latina. Uno de estos ejemplos es el debate sobre la supergentrificación o la (re) gentrificación de los barrios ya gentrificados, en gran parte impulsado por las finanzas y la nueva elite monetaria de los trabajadores del sector financiero (Butler \& Robson, 2003; Lees, 2003; Butler \& Lees 2006; Podagrosi et al., 2011). Debido al alcance limitado de la supergentrificación, que ocurre solo unas pocas ciudades globales, no merece la pena discutirlo en España y en Latinoamérica por el momento. Del mismo modo, las "políticas neoliberales de la mezcla social" tales como las que se aplicaron en el Reino Unido durante los gobiernos del "New Labour" (Bridge et al., 2012; Davidson, 2008; Lees, 2008) no se han producido en España y América Latina, razón por la cual el debate sobre sus consecuencias perjudiciales, así como los mitos detrás del proceso (Lees et al., 2012; Rose et al., 2012) es igualmente inexistente. La gentrificación de nueva construcción (new-build gentrification) es otro tema importante dentro de los debates recientes en el mundo angló- 
fono (Lambert \& Boddy, 2002; Boddy, 2007; Butler, 2007; Davidson, 2008; Davidson \& Lees, 2010; Rerat \& Lees, 2011), que no se ha abordado en ninguna publicación sobre España y América Latina. Sin embargo, en este caso, esto no responde a una ausencia del fenómeno; la gentrificación de nueva construcción ciertamente existe en Bilbao, Madrid y Barcelona, así como en el plan de reconversión de Puerto Madero en Buenos Aires o en la zona portuaria de Río de Janeiro, en pleno proceso de gentrificación. No obstante, los investigadores prefieren centrarse en las consecuencias negativas de los planes y esquemas adoptados, en lugar de contribuir a unos debates que se centran en la cuestión de si las reurbanizaciones de nueva construcción son (o no) una de las variadas expresiones de la gentrificación. A este respecto, se aplican -aunque inconscientemente- demandas tales como las expresadas por Slater (2006; 2008) acerca de la repolitización de la investigación sobre la gentrificación.

Por este motivo, se irá concentrando ahora en las dimensiones en las que los investigadores españoles y latinoamericanos aportan unas contribuciones fundamentales a la teoría anglosajona. Uno de los aspectos clave que procede esencialmente del debate de la gentrificación en España nos conduce a la relación recíproca entre la gentrificación y la migración transnacional. Hace más de una década, Loretta Lees (2000) planteó este como un tema fundamental para comprender mejor la gentrificación en las ciudades globales, pero su llamamiento a articular la gentrificación con la inmigración transnacional fue desoída, y solo muy recientemente la relación entre migración y gentrificación ha comenzado a recibir alguna atención (Hackworth \& Rekers, 2005; Murdie \& Teixeira 2011; Bacque \& Fijalkov, 2012; DeSena \& Shortell, 2012). En cambio, el nexo entre migración y gentrificación ha sido abordado ampliamente por diferentes investigadores españoles desde principios de los años 2000. Algunos de ellos adaptaron la investigación sobre segregación residencial, desigualdades urbanas y racismo institucional sufrido por inmigrantes transnacionales a partir de la perspectiva de la gentrificación, lo que significa que el concepto es útil como herramienta teórica para progresar en la investigación crítica desde el campo de las migraciones. Sin embargo, la relación entre la migración y la gentrificación en Madrid o Barcelona debe ser entendida de manera claramente diferente de los casos de París, Londres o Nueva York, dadas las múltiples diferencias en las trayectorias migratorias en cada una de las ciudades, en las propias políticas públicas y en las estructuraciones sociales, políticas y administrativas de los entornos urbanos.

Por otro lado, en las ciudades de América Latina, uno de los enfoques principales de la gentrificación puede hallarse en la reciente creación de nuevos mercados inmobiliarios, perspectiva sobre la gentrificación que no existe en los discursos anglófonos. En este sentido, responde en cierta medida a las diferentes velocidades de penetración capitalista que se pueden observar entre América Latina y el mundo anglosajón. Más que indicar tan solo la progresiva incorporación de las ciudades latinoamericanas en las relaciones mercantilizadas de producción e intercambio capitalista, la relación entre la gentrificación y la reciente creación de mercados inmobiliarios implica no obstante toda una serie de interesantes matices que deberían ser investigados a fondo. De este modo, la pregunta tradicional de investigación acerca de cómo se interrelacionan mutuamente la gentrificación, el abandono y el desplazamiento (Marcuse, 1985), podría revisarse y reformularse a través de la experiencia latinoamericana de la creación de nuevos mercados inmobiliarios. Además, este tipo de investigaciones ayudaría a desarrollar novedosas respuestas a la cuestión planteada por Slater (2012: 189) sobre cómo la teoría urbana crítica puede relacionarse con el proyecto científico de avanzar en un marco analítico, político y moral que coloque el derecho a la vivienda como un derecho humano y como una necesidad que está íntimamente relacionada con las demandas de justicia social.

A continuación, se plantea introducir las dos dimensiones centrales que juegan un papel dominante en la investigación de la gentrificación tanto en España como en América Latina y que en términos generales se ignoran en la investigación anglófona: la gentrificación simbólica relacionada con el turismo y la resistencia a la gentrificación. Referiéndonos al primer aspecto, cabe señalar que este fenómeno ha sido discutido en los 
discursos principales anglófonos, relacionando la gentrificación simbólica por el turismo y la cultura con el patrimonio artístico, cultural o arquitectónico, mediante términos como "gentrificación turística" (Gotham, 2005) y "gentrificación comercial" (Shaw, 2005; Pendlebury et al., 2009). Sin embargo, estos debates no tienen la misma carga política ni la relevancia que en el mundo de habla hispana y portuguesa. Como se ha mencionado anteriormente, las dimensiones simbólicas que preparan a los espacios urbanos para la gentrificación (en sus diferentes formas, tales como la gentrificación productiva, turística o comercial) juegan un papel importante: la transición hacia una economía de servicios, las nuevas actividades comerciales, y nuevos tipos y formas organizativas del trabajo implican que barrios anteriormente degradados se hayan reconvertido en "contenedores" que tienen una importancia simbólica para la economía del conocimiento. Con respecto a esto, las diferentes dimensiones simbólicas de gentrificación (como la gentrificación comercial) deberían ser mejor abarcadas en los discursos principales anglófonos, para reunir los fenómenos variados del actual ciclo capitalista de acumulación por desposesión. Esta perspectiva implica que la gentrificación afecta no solo a las viviendas y conjuntos residenciales, sino que comprende también la emergencia de nuevas relaciones laborales y una amplia resignificación del espacio (público) en tiempos de una reestructuración social que se basa en los principios de mercado.

Además, el mundo "latino" incorpora también nuevos enfoques emancipatorios para estudiar las relaciones entre los investigadores sociales, los movimientos sociales urbanos y la necesaria resistencia a la gentrificación. Nos recuerda que la investigación sobre la resistencia a la gentrificación puede incluir dimensiones diferentes a las tratadas recientemente en el mundo anglosajón, con respecto a la resistencia al desplazamiento (Newman \& Wyly, 2006; DeVerteuil, 2012). Los debates en España y América Latina se encuentran cerca de aquellos que se comprometen directamente con las protestas contra la gentrificación (Papen, 2012), las demandas vecinales (Maeckelbergh, 2012) y los movimientos sociales contrahegemónicos (Pruijt, 2012; Thorn, 2012). Tal perspectiva ayuda a resignificar la gentrificación desde una perspectiva comprometida que restituye las demandas ciudadanas en los estudios de las ciencias sociales.

\section{Gentrificación en España y América Latina. Observaciones finales}

Esta revisión bibliográfica ha querido proporcionar un avance sustancial en la comprensión de las variadas geografías de la gentrificación, desde el objetivo de establecer un diálogo crítico entre los discursos principales anglófonos y los debates originados en España y América Latina. En este sentido, no solo se adapta el término a las condiciones urbanas, políticas, sociales y económicas específicas, sino también proporciona una rearticulación importante que ayuda a repolitizar los estudios urbanos y los discursos sobre gentrificación (Slater, 2006; 2008; Smith, 2008; Wacquant 2008; Watt, 2008). Las discusiones presentadas han reconocido ampliamente que, cuando la gentrificación se expande a zonas urbanas fuera del mundo anglosajón, abraza las especificidades locales y crea formas simbióticas que integran discursos y prácticas existentes, así como las estructuras administrativas, políticas y sociales locales. En este sentido, las geografías de la gentrificación en las ciudades españolas y latinoamericanas proporcionan sobre todo nuevas perspectivas analíticas sobre la ofensiva de un capitalismo con unas políticas neoliberales agresivas que originan una ciudad revanchista.

Asimismo, el análisis crítico de los debates en España y América Latina podría invalidar y deslegitimar cualquier visión acrítica de la gentrificación que indique los efectos positivos de las políticas de renovación en cualquiera de las ciudades que se examinan. Al contrario, amplía las reflexiones críticas, como por ejemplo los debates acerca del derecho a la ciudad, y esto ocurre especialmente en relación con el papel que tiene el espacio público para las políticas e intervenciones urbanas $y$, por ende, para la gentrificación (Chaskin \& Joseph, 2012). Como ha sido ampliamente tratado en este artículo, las políticas neoliberales de la gentrificación (simbólica) no tienen como objetivo solo las cuestiones relacionadas con la vivienda, sino 
que se incluyen debates como el impedimento de uso del espacio público a los ciudadanos, por ejemplo, mediante su privatización y control o la disminución de la práctica de posibles actividades (formales e informales). De ahí se desprende la abundante reflexión sobre la transformación de los espacios públicos en lugares comercializados, controlados y políticamente vaciados. Por lo que el análisis de la gentrificación a través del papel que juega el espacio público en el mundo 'latino' es una propuesta esencial. El desalojo de la población "indeseable" nos recuerda cómo la renovación urbana, literalmente, puede ser evaluada como un proceso de "higienización social" que desplaza y criminaliza las prácticas sociales y políticas no deseadas. En este sentido, la apropiación del espacio público hace que sea necesario volver a abordar las diferentes dimensiones de desplazamiento y su interrelación con el abandono y la gentrificación (Marcuse, 1985).

Otra demanda sugerente que nace de los discursos 'latinos' no considera la gentrificación como una consecuencia ineludible de las políticas urbanas neoliberales. Por ejemplo, algunos de los gobiernos progresistas de América Latina están buscando formas de reformar el capitalismo agresivo. Estos experimentan con nuevos enfoques para reorientar las políticas urbanas mediante la construcción de las bases de unas sociedades más inclusivas. Los "espacios de esperanza" (Harvey, 2000) resultantes podrían tener un poder transformador, proporcionando una mejor comprensión de las incoherencias, falacias y rupturas de los discursos dominantes del capitalismo neoliberal contemporáneo. Esta observación requiere necesariamente más investigación sobre la resistencia a la gentrificación, por ejemplo en países como Venezuela y Bolivia, donde la gentrificación no ha sido estudiada por ningún investigador hasta ahora.

Pero también nos recuerdan que la investigación de la gentrificación en el mundo "latino" surge de las luchas contra el poder destructivo que la neoliberalización tiene para las mayorías sociales. Estos debates, anteriores a la difusión del concepto de gentrificación, nos proporcionan la única manera en que se ha abordado la gentrificación en el mundo "latino", es decir, conceptualizarlo como consecuencia negativa del capitalismo contemporáneo. Por lo menos desde el estaIlido de la segunda Gran Recesión en 2008 e impulsado por la propagación mundial del movimiento "Occupy", la defensa de los bienes comunes y las demandas por el derecho a la vivienda se han incrementado cada vez más y ganan terreno en todo el mundo. No obstante, en España y América Latina muchas de estas 'nuevas' demandas reflejan la práctica social común: la ocupación de tierras, del espacio urbano y de edificios vacíos es una estrategia profundamente arraigada para reclamar el derecho a la ciudad en América Latina (Zibechi, 2008); o, siguiendo el curso del movimiento de los "indignados", la ocupación de edificios abandonados se ha difundido ahora a todas las principales ciudades españolas. Tal acción contrahegemónica rompe con algunos aspectos claves de la dominación capitalista (Holloway, 2010), por lo que las alternativas políticas y sociales al capitalismo neoliberal maduran y se difunden en la práctica diaria.

Como Maeckelbergh (2012: 666) afirma: "los movimientos dibujan un continuo que va desde la gentrificación a la crisis económica, mediante la vinculación tanto con el 'neoliberalismo', identificando así el origen de los actuales problemas de vivienda no como el fracaso de los mercados financieros, sino como el 'neoliberalismo' en sí". Esta idea representa ahora un consenso creciente y ya no se circunscribe a los activistas de izquierda y a los que tradicionalmente ocupan y liberan viviendas, cada vez incluye más hogares 'comunes' de clase media, así como de la 'clase creativa' que igualmente luchan contra la gentrificación, aunque ellos anteriormente hayan sido (mal)-utilizados para justificar la gentrificación en su nombre (Novy \& Coulomb, 2012). Así, las nuevas apropiaciones del lenguaje que se están produciendo, reúnen a investigadores críticos, expertos en gentrificación y a los movimientos sociales, en España, América Latina y el mundo anglosajón.

\section{Referencias bibliográficas}

ABELLÁN, J.; SEQUERA, J. \& JANOSCHKA, M. Occupying the \#hotelmadrid: a laboratory for urban resistance. Social Movement Studies: Journal of Social, Cultural and 
Political Protest, 2012, Vol. 11, № 3-4, p. 320-326.

AGUIRRE, C. y MARCHANT, C. Proceso de renovación urbana de Santiago, una mirada a los demandantes de vivienda. En: DE MATTOS, C. \& HIDALGO, R. (editores). Santiago de Chile. Movilidad espacial y reconfiguración metropolitana. Santiago de Chile: Serie GEOlibros, Instituto de Geografía, Pontificia Universidad Católica de Chile, 2007, p. 45-60.

ÁlVAREZ-RIVADUlla, M. Golden ghettos: gated communities and class residential segregation in Montevideo, Uruguay. Environment and Planning A, 2007, Vol. 39, p. 47-63.

ARBACl, S. Ethnic segregation, housing systems and welfare regimes in Europe. International Journal of Housing Policy, 2007, Vol. 7, No 4, p. 401-33.

ARBACl, S. (Re)viewing ethnic residential segregation in Southern European cities: housing and urban regimes as mechanisms of marginalization. Housing Studies, 2008, Vol. 23, № 4, p. 589-613.

ARBACI, S. \& MALHEIROS, J. De-segregation, peripheralization and the social exclusion of immigrants: Southern European cities in the 1990s. Journal of Ethnic and Migration Studies, 2010, Vol. 36, № 2, p. 227-255.

ATKINSON, R. \& BRIDGE, G. Introduction. In: ATKINSON, R. \& BRIDGE, G. (editors). Gentrification in a global context: the new urban colonialism, London: Routledge, 2005, p. 1-17.

ÁVILA, D. y MALO, M. ¿Quién puede habitar la ciudad? Fronteras, gobierno y transnacionalidad en los barrios de Lavapiés y San Cristóbal. In: OBSERVATORIO METROPOLITANO (editor). Madrid, ¿la suma de todos? Globalización, territorio, desigualdad. Madrid: Traficantes de Sueños, 2008, p. 505632.

BACQUÉ, M. \& FIJALKOW, Y. Social mix as the aim of a controlled gentrification process: the example of Goutte d'Or district in Paris. In: BRIDGE, G,; BUTLER, T. \& LEES, L. (editors). Mixed communities. Gentrification by stealth?, Bristol: Policy Press, 2012.

BAILEY, N. The challenge and response to global tourism in the post-modern era: the commodification, reconfiguration and mutual transformation of Habana Vieja, Cuba. Urban Studies, 2008, Vol. 45. № 5/6, p. 1079-1096.

BARAÑANO, M.; RIESCO, A.; ROMERO, C. y GARCÍA, J. Globalización, inmigración transnacional y reestructuración de la región metropolitana de Madrid. Estudio del barrio de Embajadores. Madrid: Edición GPS, 2006.

BÉLANGER, H. Vivir en un centro histórico en Latinoamérica. Percepciones de los hogares de profesionales en la Ciudad de Puebla. Estudios Demográficos y Urbanos, 2008, Vol. 23, № 2, p. 415-440.

BIDOU-ZACHARIASEN, C. De volta à cidade: dos processos de gentrificação às políticas de 'revitalização' dos centros urbanos. São Paulo: Annablume, 2006.

BODDY, M. Designer neighbourhoods: new-build residential development in nonmetropolitan UK cities - the case of Bristol. Environment and Planning A, 2007, Vol. 39, No 1, p. 86-105.

BOIXADER, J. Nuevas tecnologías y renovación urbana: luces y sombras del distrito 22@ Barcelona. Scripta Nova: Revista electrónica de Ciencias Sociales, 2004, Vol. 8, № 170 (34). Disponible en internet: http://www. ub.edu/geocrit/sn/sn-170-34.htm

BORSDORF, A. \& HIDALGO, R. From polarization to fragmentation. Recent changes in Latin American urbanization. In: VAN LINDERT, P. \& VERKOREN, O. (editors). Decentralized development in Latin America: experiences in local governance and local development. Amsterdam: Springer, 2010, p. 365-378.

BORTOLOZZI, A. Educación ambiental, territorio urbano y nuevas prácticas socioespaciales: repensando el proceso de "gentrificación" para la sustentación de las ciudades brasileñas. Utopía y Praxis Latinoamericana, 2009, Vol. 14, No 44, p. 125-129. 
BOTELHO, T. Revitalização de centros urbanos no Brasil: uma análise comparativa das experiências de Vitória, Fortaleza e São Luís. EURE, 2005, Vol. 31, № 93, p. 53-71.

BOUZAROVSKI, S.; HAASE, A.; Hall, R.; STEINFÜHRER, A.; KABISCH, S. \& OGDEN, $P$. Household structure, migration trends, and residential preferences in inner-city León, Spain: unpacking the demographics of reurbanization. Urban Geography, 2010, Vol. 31, $\mathrm{N}^{\circ} 2$, p. $211-235$.

BRENNER, N.; PECK, J. \& THEODORE, $\mathrm{N}$. Variegated neoliberalization: geographies, modalities, pathways. Global Networks, 2010a, Vol. 10, No 2, p. 182-222.

BRENNER, N.; PECK, J. \& THEODORE, N. After neoliberalization? Globalizations, 2010b, Vol. 7, No 3, p. 327-345.

BRIDGE, G.; BUTLER, T. \& LEES, L. (editors). Mixed communities. Gentrification by stealth?, Bristol: Policy Press, 2012.

BROMLEY, R. \& MACKIE, P. Displacement and the new spaces for informal trade in the Latin American city centre. Urban Studies, 2009, Vol. 46, No 7, p. 1485-1506.

BUTLER, T. Re-urbanizing London Docklands: gentrification, suburbanization or new urbanism? International Journal of Urban and Regional Research, 2007, Vol. 31, No 4, p. 759-781.

BUTLER, T. \& LEES, L. Super- gentrification in Barnsbury, London: globalization and gentrifying global elites at the neighbourhood level. Transactions of the Institute of British Geographers, 2006, Vol. 31, № 4, p. 467-487.

BUTLER, T. \& ROBSON, G. Negotiating their way in: the middle classes, gentrification and the deployment of capital in a globalizing metropolis. Urban Studies, 2003, Vol. 40, No 9, p. 1791-1809.

BUZAR, S.; OGDEN, P.; HALL, R.; HAASE, A.; KABISCH, S. \& STEINFÜHRER, A. Splintering urban populations: emergent landscapes of reurbanization in four Euro- pean cities. Urban Studies, 2007, Vol. 44, No 4, p. 651-677.

CABRALES, L. The historic center of Morelia: a case of successful negotiation. Journal of Latin American Geography, 2005, Vol. 4, № 2, p. 35-56.

CALDEIRA, T. City of walls. Crime, segregation, and citizenship in São Paulo. Berkeley, CA: University of California Press, 2000.

CÁNOVES, G. y BLANCO, A. Teletrabajo, género y gentrificación o elitización en los espacios rurales: nuevos usos y nuevos protagonistas. Los casos de Cataluña y Ardèche (Francia). Geographicalia, 2006, № 50, p. 27-44.

CAÑEDO, M. Lavapiés, área de rehabilitación preferente. Políticas culturales y construcción del lugar. Madrid: Tesis doctoral, Departamento de Antropología Social, Universidad Complutense de Madrid, 2006.

CARRIÓN, F. El centro histórico como proyecto y objeto de deseo. EURE, 2005, Vol. $31, N^{\circ} 93$, p. 89-100.

CASGRAIN, A. y JANOSCHKA, M. Gentrificación y resistencia en las ciudades latinoamericanas. El ejemplo de Santiago de Chile. Andamios. Revista de investigación social, 2013, Vol. 10, No 22, p. 19-44.

CASTELLS, M. (editor). Imperialismo y urbanización en América Latina. Barcelona: Gustavo Gili, 1973.

CASTELLS, M. La cuestión urbana. Madrid: Siglo XXI, 1974 [1972].

CASTELLS, M. Movimientos sociales urbanos. Madrid: Siglo XXI, 1974.

CASTELLS, M. The city and the grassroots: a cross-cultural theory of urban social movements. Berkeley: University of California Press, 1983.

CATALÁN, B.; SAURí, D. \& SERRA, P. Urban sprawl in the Mediterranean? Patterns of growth and change in the Barcelona Metropolitan Region 1993-2000. Landscape and 
Urban Planning, 2008, Vol. 85, No 3/4, p. 174-184.

CAVALCANTI, M. Do barraco à casa: tempo, espaço e valor(es) em uma favela consolidada. Revista Brasileira de Ciências Sociais, 2009, Vol. 24, No 69, p. 69-80.

CAVIA, B.; GATTI, G.; MARTÍNEZ DE ALBÉNIZ, I. \& SEGUEL, A. Crisis of the social and emergence of sociality in the new scenarios of identity. The San Francisco district of Bilbao. Papeles del CEIC, 2008, Vol. 39/2. Disponible en Internet: http://redalyc. uaemex.mx/pdf/765/76501003.pdf

CHASKIN, R. \& JOSEPH, M. "Positive" gentrification, social control and the "right to the city' in mixed-income communities: uses and expectations of space and place. International Journal of Urban and Regional Research, 2012, Vol. 37, № 2, p. 480-502.

CHECA-ARTASU, M. Gentrificación y cultura: algunas reflexiones. Biblio $3 W$. Revista Bibliográfica de Geografía y Ciencias Sociales, 2011, Vol. 15, No 914. Disponible en Internet: http://www.ub.es/geocrit/ b3w-914.htm

CONTRERAS, Y. La recuperación urbana y residencial del centro de Santiago: nuevos habitantes, cambios socioespaciales significativos. EURE, 2011, Vol. 37, No 112, p. 89-113.

COOK, I. Mobilizing urban policies: the policy transfer of US business improvement districts to England and Wales. Urban Studies, 2008, Vol. 45, № 4, p. 773-795.

CROSSA, V. Resisting the entrepreneurial city: street vendors struggle in Mexico City's historic center. International Journal of Urban and Regional Research, 2009, Vol. 33, № 1 , p. 43-63.

CROWLEY, W. Modelling the Latin American city. Geographical Review, 1998, Vol. 88, № 1, p. 127-130.

CUENYA, B. y CORRAL, M. Empresarialismo, economía del suelo y grandes proyectos urbanos: el modelo de Puerto Madero en Buenos Aires. EURE, 2011, Vol. 37, No 111, p. 25-45.
DAVIDSON, M. Spoiled mixture - where does state-led 'positive' gentrification end? Urban Studies, 2008, Vol. 45, № 12, p. 2385-2405.

DAVIDSON, M. \& LEES, L. New-build gentrification: its histories, trajectories, and critical geographies. Population, Space and Place, 2010, Vol. 16, № 5, p. 395-411.

DAVIS, M. Planet of slums. London: Verso, 2006.

DEGEN, M. \& GARCÍA, M. The transformation of the 'Barcelona model': an analysis of culture, urban regeneration and governance. International Journal of Urban and Regional Research, 2012, Vol. 36, № 5, p. 1022-1038.

DELGADILLO, V. Patrimonio urbano y turismo cultural en la Ciudad de México: las chinampas de Xochimilco y el Centro Histórico. Andamios. Revista de investigación social, 2009, Vol. 6, № 12, p. 69-94.

DELGADILLO, V. Patrimonio histórico y tugurios. Las políticas habitacionales y de recuperación de los centros históricos de Buenos Aires, Ciudad de México y Quito. Universidad Autónoma de la Ciudad de México, México, 2012.

DELGADO, M. La artistización de las políticas urbanas: el lugar de la cultura en las dinámicas de reapropiación capitalista de la ciudad. Scripta Nova: Revista electrónica de Geografía y Ciencias Sociales, 2008, Vol. XII, $\mathrm{N}^{\circ} 270$ (69). Disponible en Internet: http:// www.ub.edu/geocrit/sn/sn-270/sn-270-69.htm

DEL RIO, V. Urban design and the future of public space in the Brazilian city. Focus, 2004, Vol. 1, p. 34-42.

DESENA, J. \& SHORTELL, T. (editors). The world in Brooklyn. Gentrification, immigration and ethnic politics in a global city. Lanham, MD: Lexington Books, 2012.

DEVERTEUIL, G. Resisting gentrificationinduced displacement: advantages and disadvantages to 'staying put' among non-profit social services in London and Los Angeles. Area, 2012, Vol. 42, № 2, p. 208-216. 
DÍAZ ORUETA, F. Madrid: urban regeneration projects and social mobilization. Cities, 2007, Vol. 24, № 3, p. 183-193.

DÍAZ ORUETA, F. \& FAINSTEIN, S. The new mega-projects: genesis and impacts. International Journal of Urban and Regional Research, 2008, Vol. 32, No 4, p. 759-767.

DÍAZ ORUETA, F.; LOURÉS, M.; RODRÍGUEZ, C. y DEVALLE, V. Ciudad, territorio y exclusión social. Las políticas de recualificación urbana en la ciudad de Buenos Aires. Reis. Revista Española de Investigaciones Sociológicas, 2003, Vol. 26, No 103, p. 159-185.

DÍAZ PARRA, I. Movimientos vecinales contra la gentrificación y transformaciones en la política local de Sevilla. Los casos de El Pumarejo y San Bernardo. Scripta Nova. Revista electrónica de Geografía y Ciencias Sociales, 2008. Disponible en Internet: http:// www.ub.edu/geocrit/-xcol/8.htm

DÍAZ PARRA, I. Procesos de gentrificación en Sevilla en la coyuntura reciente. Análisis comparado de tres sectores históricos: San Luis-Alameda, Triana y San Bernardo (2000-2006). Scripta Nova. Revista electrónica de Geografía y Ciencias Sociales, 2009, Vol. 13, No 304. Disponible en Internet: http://www.ub.edu/geocrit/sn/sn-304.htm

DÍAZ PARRA, I. Cambios en la geografía social de Sevilla 1981-2000. Cuadernos Geográficos, 2010, Vol. 46, № 1, p. 139-161.

DONOVAN, M. Informal cities and the contestation of public space: the case of Bogotá's street vendors, 1988-2003. Urban Studies, 2008, Vol. 45, № 1, p. 29-51.

DOT, E.; CASELLAS, A. y PALLARES-BARBERA, M. Gentrificación productiva en Barcelona: efectos del nuevo espacio económico. Actas de la IV Jornada de Geografía Económica, 2010, Disponible en Internet: http://age. ieg.csic.es/geconomica/IVJornadasGGELeon/ Comunicaciones $\% 20$ Jornadas $\% 20$ de $\% 20$ Leon/I\%20Ponencia/Dot-Casellas-Pallar.pdf.

DOUCET, B.; VAN KEMPEN, R. \& VAN WEESEP, J. "We're a rich city with poor people": municipal strategies of new-build gentrification in Rotterdam and Glasgow. En- vironment and Planning A, 2011a, Vol. 43, $\mathrm{N}^{\circ}$ 6, p. 1438-1454.

DOUCET, B.; VAN KEMPEN, R. \& VAN WEESEP, J. Resident perceptions of flagship waterfront regeneration: the case of Kop van Zuid in Rotterdam. Tijdschrift voor Economische en Sociale Geografie, 2011b, Vol. 102, N ${ }^{\circ}$ 2 , p. 125-145.

DUQUE, R. La difusión del concepto gentrification en España: reflexión teórica y debate terminológico. Biblio 3W. Revista Bibliográfica de Geografía y Ciencias Sociales, 2010a, Vol. 15, № 875. Disponible en Internet: http://www.ub.edu/geocrit/b3w-875.htm.

DUQUE, R. Procesos de gentrification de cascos antiguos de España: El Albaicín de Granada. Granada: Universidad de Granada, Departamento de sociología, 2010b. Tesis doctoral inédita.

ERGUN, N. Gentrification in Istanbul. Cities, 2004, Vol. 21, № 5, p. 391-405.

EVANS, G. Creative cities, creative spaces and urban policy. Urban Studies, 2009, Vol. $46, N^{\circ}$ 5/6, p. 1003-1040.

FORD, L. A new and improved model of Latin American city structure. Geographical Review, 1996, Vol. 86, №3, p. 437-440.

FRANQUESA, J. Vaciar y llenar, o la lógica espacial de la neoliberalización. Reis. Revista Española de Investigaciones Sociológicas, 2007, Vol. 30, No 118, p. 123-150.

FRASER, B. Madrid's Retiro Park as publicly-private space and the spatial problems of spatial theory. Social and Cultural Geography, 2007, Vol. 8, No 5, p. 673-700.

FRÚGOLI, H. \& SKLAIR, J. The Luz district in São Paulo: anthropological questions on the phenomenon of gentrification. Paper presented to the ninth International Conference of the Brazilian Studies Association, 2008. Disponible en Internet: http://www.brasa.org/ Documents/BRASA_IX/Heitor-Frugoli-JessicaSklair.pdf

FUJITSUKA, Y. Gentrification and neighbourhood dynamics in Japan: the case of 
Kyoto. In: ATKINSON, R. \& BRIDGE, G. (eds.) Gentrification in a global context: the new urban colonialism. London: Routledge, 2005, p. 139-154.

GAFFNEY, C. Mega-events and socio-spatial dynamics in Rio de Janeiro, 1919-2016. Journal of Latin American Geography, 2010, Vol. 9, No 1, p. 7-29.

GARCíA, L. Elitización: propuesta en español para el término gentrificación. Biblio 3W. Revista Bibliográfica de Geografía y Ciencias Sociales, 2001, Vol VI, No 332. Disponible en internet: http://www.ub.es/geocrit/ b3w-332.htm

GARCÍA, L. ¿De cabañas a palacios? Vivienda y proceso de elitización en El CaboLos Llanos (Santa Cruz de Tenerife, Canarias). Scripta Nova. Revista electrónica de Geografía y Ciencias Sociales, 2003, Vol. 8 № 146 (075) Disponible en internet: http://www. ub.es/geocrit/sn/sn-146(075).htm

GARCÍA, L.; SMITH, N. \& MEJÍAS, M. Gentrification, displacement, and tourism in Santa Cruz de Tenerife. Urban Geography, 2007, Vol. 28, № 3, p. 276-98.

GÁRRIZ, I. The right to the city as a conceptual framework to study the impact of North-South Migration. Recreation and Society in Africa, Asia and Latin America, 2011, Vol. 2, No 1, p. 3-33.

GHERTNER, A. Gentrifying the state, gentrifying participation: elite governance programs in Delhi. International Journal of Urban and Regional Research, 2011, Vol. 35, No 3, p. 504-32.

GIGLIA, A. Gated communities in Mexico City. Home Cultures, 2008, Vol. 5, № 1, p. 65-84.

GILBERT, A. The Latin American city. London: The British Library, 1994.

GLASS, R. London: aspects of change. London: MacGibbon \& Kee, 1964.

GÓMEZ, M. Reflective images: the case of urban regeneration in Glasgow and Bilbao.
International Journal of Urban and Regional Research, 1998, Vol. 22, № 1, p. 106-21.

GÓMEZ, M. El barrio de Lavapiés, laboratorio de interculturalidad. Dissidences. Hispanic Journal of Theory and Criticism, 2006, Vol. 1. Disponible en Internet: http:// digitalcommons.bowdoin.edu/dissidences/vol1/iss2/12/

GÓMEZ, M. \& GONZÁLEZ, S. A reply to Beatriz Plaza's "The Guggenheim-Bilbao Museum Effect". International Journal of Urban and Regional Research, 2001, Vol. 25, No 4, p. 898-900.

GONÇALVES, R. O mercado de aluguel nas favelas cariocas e sua regularização numa perspectiva histórica. GEOgraphia, 2011, Vol. 13, № 26, p 114-35.

GONZÁLEZ, S. Bilbao and Barcelona 'in motion'. How urban regeneration 'models' travel and mutate in the global flows of policy tourism. Urban Studies, 2011, Vol. 48, No 7, p. 1397-1418.

GONZÁLEZ-HERNÁNDEZ, G. La revitalización del Centro Histórico de Zacatecas y la conciencia social. Economía, Sociedad y Territorio, 2009, Vol. 9, № 30, p. 473-513.

GOTHAM, K. Tourism gentrification: the case of New Orleans' Vieux Carré (French Quarter). Urban Studies, 2005, Vol. 42, No 7, p. 1099-1121.

GOULART, R. Processo de reabilitação e renovação urbana na cidade do Rio de Janeiro e suas perspectivas. Scripta Nova. Revista Electrónica de Geografía y Ciencias Sociales. 2005, Vol. 9, No 194 (44). Disponible en Internet: http://www.ub.es/geocrit/sn/ sn-19444.htm

GUILLAMÓN, I. ¿Del Manchester Catalán al Soho Barcelonés? La renovación del barrio de PobleNou en Barcelona y la cuestión de la vivienda. Scripta Nova. Revista Electrónica de Geografía y Ciencias Sociales, 2003, Vol. 8, $\mathrm{N}^{\circ} 146$ (137). Disponible en internet: http:// www.ub.es/geocrit/sn/sn-146(137).htm

HAASE, A. Reurbanization - an analysis of the interaction between urban and demographic changes as a comparison between 
European cities. Die Erde, 2008, Vol. 139, No 4, p. 309-332.

HACKWORTH, J. Post recession gentrification in New York City. Urban Affairs Review, 2002, Vol. 37, № 6, p. 815-843.

HACKWORTH, J. \& REKERS, J. Ethnic packaging and gentrification. the case of four neighbourhoods in Toronto. Urban Affairs Review, 2005, Vol. 41, № 2, p. 211-236.

HARRIS, A. From London to Mumbai and back again: gentrification and public policy in comparative perspective. Urban Studies, 2008, Vol. 45, No 12, p. 2407-2428.

HARVEY, D. Spaces of hope. Berkeley: University of California Press, 2000.

$\mathrm{HE}, \mathrm{S}$. New-build gentrification in central Shanghai: demographic changes and socioeconomic implications. Population, Space and Place, 2010, Vol. 16, No 5, p. 345-361.

HERNÁNDEZ-MEDINA, E. Social inclusion through participation: the case of the participatory budget in São Paulo. International Journal of Urban and Regional Research, 2010, Vol. 34, No 3, p. 512-532.

HERZER, H. (editor). Con el corazón mirando al sur: transformaciones en el sur de la ciudad de Buenos Aires. Buenos Aires: Espacio Editoria, 2008.

HIDALGO, R. Los centros históricos y el desarrollo inmobiliario: las contradicciones de un negocio exitoso en Santiago de Chile. Scripta Nova. Revista Electrónica de Geografía y Ciencias Sociales, 2010, Vol. 14, N 331 (85). Disponible en Internet: http://www. ub.es/ geocrit/sn/sn-331/sn-331-85.htm

HIDALGO, R. y ARENAS, F. Negocios inmobiliarios y la transformación metropolitana de Santiago de Chile: Desde la renovación del espacio central hasta la periferia expandida. Revista Geográfica de América Central, 2011, Vol. 47, No 2(E). Disponible en Internet: http://www.revistas.una.ac.cr/index.php/ geografica/article/view/2207

HIERNAUX, D. A reapropriação de bairros da Cidade do México pelas classes médias: em direção a uma gentrificação? In: BIDOU, C.; HIERNAUX, D. \& RIVIĚRE, H. (editores). De volta à cidade: dos processos de gentrificação às políticas de 'revitalização' dos centros urbanos, São Paulo: Annablume, 2006, p. 229-264.

HOLLOWAY, J. Crack capitalism. London: Pluto Press, 2010.

INZULZA-CONTARDO, J. "Latino gentrification"? Focusing on physical and socioeconomic patterns of change in Latin American inner cities. Urban Studies, 2012, Vol. 49, No 10, p. 2085-2107.

IRAZÁBAL, C. One size does not fit all: land markets and property rights for the construction of the just city. International Journal of Urban and Regional Research, 2009, Vol. $33, N^{\circ} 2$, p. 558-563.

ISLAM, T. Outside the core: gentrification in Istanbul. In: ATKINSON, R. \& BRIDGE, G. (editors). Gentrification in a global context: the new urban colonialism, London: Routledge, 2005 .

IVO, A. Jardins do Éden: Salvador, uma cidade global-dual. Cadernos CRH, 2012, Vol. 25, No 64, p. 131-146.

JACKIEWICZ, E. \& CRANE, T. Destination Panama: an examination of the migrationtourism-foreign investment nexus. Recreation and Society in Africa, Asia and Latin America, 2010, Vol. 1, No 1, p. 5-29.

JANOSCHKA, M. El nuevo modelo de la ciudad latinoamericana: fragmentación y privatización. EURE, 2002, Vol. 28, № 85, p. 11-29.

JANOSCHKA, M. The contested spaces of lifestyle mobilities: regime analysis as a tool to study political claims in Latin American retirement destinations. Die Erde, 2009, Vol. 140, No 3, p. 251-274.

JANOSCHKA, M. Geografías urbanas en la era del neoliberalismo. Una conceptualización de la resistencia local a través de la participación y la ciudadanía urbana. Investigaciones Geográficas, 2011, Vol. 76, p. 118-132. 
JANOSCHKA, M. \& BORSDORF, A. Condominios fechados and barrios privados: the rise of private residential neighbourhoods in Latin America. In: FRANTZ, K.; WEBSTER, C. \& GLASZE, G. (editors). Private city fragments. The global spread of (gated) proprietary neighbourhoods, London: Routledge, 2006.

JARAMILLO, S. Reflexiones sobre las políticas de recuperación del centro (y del centro histórico) de Bogotá. Documento CEDE, 2006, No 2006-40, Universidad de los Andes, Bogotá.

JONES, G. \& BROMLEY, R. The relationship between urban conservation programmes and property renovation: evidence from Quito, Ecuador. Cities, 1996, Vol. 13, No 6, p. 373-385.

JONES, G. \& VARLEY, A. The contest for the city centre: street traders versus buildings. Bulletin of Latin American Research, 1994, Vol. 13, No 1, p. 27-44.

JONES, G. \& VARLEY, A. The reconquest of the historic centre: urban conservation and gentrification in Puebla, Mexico. Environment and Planning A, 1999, Vol. 31, № 9, p. 1547 1566.

JUSTO, A. Transformaciones en el barrio de Malasaña. Hacia la gentrificación. Viento Sur, 2011, № 116, p. 73-79.

KAZTMAN, R. \& RIBEIRO, L. Metrópoles e sociabilidade: os impactos das transformações socioterritoriais das grandes cidades na coesão social dos países da América Latina. Cadernos Metrópole, 2008, Vol. 12, No 20, p. 241-261.

LAMBERT, C. \& BODDY, M. Transforming the city: post-recession gentrification and re-urbanization. Paper presented at the Conference on Upward Neighbourhood Trajectories: Gentrification in the New Century, 2627 September, University of Glasgow, 2002.

LEES, L. A reappraisal of gentrification: towards a "geography of gentrification". Progress in Human Geography, 2000, Vol. 24, № 3, p. 389-408.
LEES, L. The ambivalence of diversity and the politics of urban renaissance: the case of youth in downtown Portland, Maine. International Journal of Urban and Regional Research, 2003, Vol. 27, №3, p. 613-634.

LEES, L. Gentrification and social mixing: towards an inclusive urban renaissance? Urban Studies, 2008, Vol. 45, № 12, p. 24492470 .

LEES, L. The geography of gentrification. Thinking through comparative urbanism. Progress in Human Geography, 2012, Vol. 38, No 2, p. 155-171.

LEES, L.; BUTLER, T. \& BRIDGE, G. Introduction: mixed communities and gentrification. In: BRIDGE, G.; BUTLER, T. \& LEES, L. (editors). Mixed communities. Gentrification by stealth?, Bristol: Policy Press, 2012, p. 1-16.

LEES, L.; SLATER, T. \& WYLY, E. Gentrification. London: Routledge, 2008.

LEITE, R. A exaustão das ciudades. Antinobrecimento e intervenções urbanas em cidades brasileiras e portuguesas. Revista Brasileira de Ciências Sociais, 2010, Vol. 25, $N^{\circ}$ 72, p. 73-88.

LIMA, C. Una mirada crítica a la zona portuaria de Río de Janeiro. Revista Bitácora Urbano Territorial, 2010, Vol. 17, $\mathrm{N}^{\circ} 2$, p. 23-54.

LOPES DE SOUZA, M. Fobópole: O medo generalizado ea militarização da questão urbana. Rio de Janeiro: Bertrand Brasil, 2008.

LÓPEZ, I. y RODRíGUEZ, E. Fin de ciclo. Financiarización, territorio y sociedad de propietarios en la onda larga del capitalismo hispano (1959-2010). Madrid: Traficantes de Sueños, 2010.

LÓPEZ, I. \& RODRíGUEZ, E. The Spanish model. New Left Review, 2011, 69.3. Disponible en Internet: http://newleftreview.org/ II/69/isidro-lopez-emmanuel-rodriguez-thespanish-model

LÓPEZ-MORALES, E. Real estate market, state-entrepreneurialism and urban policy in the 'gentrification by ground rent disposses- 
sion' of Santiago de Chile. Journal of Latin American Geography, 2010, Vol. No 9.1, p. 145-173.

LÓPEZ-MORALES, E. Gentrification by ground rent dispossession: the shadows cast by large-scale urban renewal in Santiago de Chile. International Journal of Urban and Regional Research, 2011, Vol. 35, No 2, p. 330-357.

LÜTZELER, R. Population increase and "new-build gentrification" in central Tokyo. Erdkunde, 2008, Vol. 62, No 4, p. 287-299.

MAECKELBERGH, M. Mobilizing to stay put: housing struggles in New York City. International Journal of Urban and Regional Research, 2012, Vol. 36, No 4, p. 655-673.

MALOUTAS, T. Contextual diversity in gentrification research. Critical Sociology, 2011, Vol. 38, № 1, p. 33-48.

MANDRINI, M.; CAPDEVIELLE, J. y CECONATO, D. Políticas neoliberales y resistencia en el territorio. Córdoba, Argentina. Urbano, 2010, Vol. 22, p. 69-77.

MARCUSE, P. Gentrification, abandonment, and displacement: connection, causes, and policy responses in New York City. Journal of Urban and Contemporary Law, 1985, Vol. 28, No 1, p. 195-240.

MARSHALL, T. Transforming Barcelona. London: Routledge, 2004.

MARTÍNEZ, A. y LEAL, J. La segregación residencial, un indicador espacial confuso en la representación de la problemática residencial de los inmigrantes económicos: el caso de la Comunidad de Madrid. ACE: Architecture, City and Environment, 2008, Vol. 3, No 8, p. 53-64.

MARTÍNEZ, M. The citizen participation of urban movements in spatial planning: a comparison between Vigo and Porto. International Journal of Urban and Regional Research, 2011, Vol. 35, № 1, p. 147-171.

MARTÍNEZ, S. El retorn al centre de la ciutat. La reestructuració del Raval entre la renovació i la gentrificació. Barcelona: Publicacions de la Universitat de Barcelona, 2001.

MCCANN, E. Urban policy mobilities and global circuits of knowledge: toward a research agenda. Annals of the Association of American Geographers, 2011, Vol. 101, № 1, p. 107-130.

MENEZES, M. \& MONTEIRO, G. Reestruturação dos sistemas de movimento e da logística e seus impactos regionais e urbanos no território paulista. Scripta Nova. Revista Electrónica de Geografía y Ciencias Sociales, 2010, Vol. 14, No 331(97). Disponible en Internet: http://www.ub.edu/geocrit/sn/sn-331/ sn-331-23.htm

MIDDLETON, A. Informal traders and planners in the regeneration of historic city centres: the case of Quito, Ecuador. Progress in Planning, 2003, Vol. 59, N 2, p. 71-123.

MONCLÚS, F. The Barcelona model: and an original formula? From "reconstruction" to strategic urban projects (1979-2004). Planning Perspectives, 2003, Vol. 18, No 4, p. 399-421.

MONTEIRO, J. \& DE ANDRADE, J. Porto Maravilha a contrapelo. Disputas soterradas pelo grande projeto urbano. e-metropolis. Revista Electrónica de Estudos Urbanos e Regionais, 2012, Vol. 3, No 8, p. 21-31.

MONTERRUBIO, A. Habitat popular, renovación urbana y movimientos sociales en barrios céntricos de la Ciudad de México 1985-2006. México: Tesis doctoral, Departmento de Sociología, Universidad Autónoma Metropolitana, 2009.

MOREH, C. Gentrification and urban heritage. The case of Albayzín. Budapest: Central European University of Budapest, 2011.

MORELL, M. Fent barri: heritage tourism policy and neighbourhood scaling in Ciutat de Mallorca. Etnográfica, 2009, Vol. 13, № 2, p. 343-372.

MUÑOZ, F. Lock living: urban sprawl in Mediterranean cities. Cities, 2003, Vol. 20, No 6, p. 381-385. 
MUÑOZ, O. El proceso de gentrificación en el municipio de Madrid (1996-2001). En: GALLEGO, S. y GÓMEZ, M. (editores). Igualdad, desarrollo y cooperación, Toledo: Asociación castellano-manchega de Sociología, 2009, p. 317-332.

MURDIE, R. \& TEIXEIRA, C. The impact of gentrification on ethnic neighbourhoods in Toronto: a case study of Little Portugal. Urban Studies, 2011, Vol. 48, No 1, p. 61-83.

NAREDO, J. y MONTIEL, A. El modelo inmobiliario español y su culminación en el caso valenciano. Barcelona: Icaria, 2011.

NELLE, A. Museality in the urban context: an investigation of museality and musealization processes in three Spanish-colonial World Heritage Towns. Urban Design International, 2009, Vol. 14, No 3, p. 152-171.

NERY, N. \& MOURA DE CASTILHO, C. Comunidade do Pilar e a revitalização do bairro do Recife. Possibilidades de inclusão socioespacial dos moradores ou gentrificação. Humanae, 2008, Vol. 1, No 2, p. 1936.

NEWMAN, K. \& WYLY, E. The right to stay put, revisited: gentrification and resistance to displacement in New York City. Urban Studies, 2006, Vol. 43, No 1, p. 23-57.

NOBRE, E. Urban regeneration in Brazil: historical preservation, tourism development and gentrification in Salvador da Bahia. Urban Design International, 2002, Vol. 7, № 2, p. 109-124.

NOVY, J. \& COULOMB, C. Struggling for the right to the (creative) city in Berlin and Hamburg: new urban social movements, new 'spaces of hope'? International Journal of Urban and Regional Research, 2013, Vol. 37, No 5, p. 1816-1838.

OLIVEIRA, N. \& GAFFNEY, C. Rio de Janeiro e Barcelona: os limites do paradigma olímpico. Biblio 3W. Revista Bibliográfica de Geografía y Ciencias Sociales, 2010, Vol. 15, $N^{\circ} 895$ (17). Disponible en Internet: http:// www.ub.es/geocrit/b3w-895/b3w-895-17.htm
PAPEN, U. Commercial discourses, gentrification and citizens' protest: the linguistic landscape of Prenzlauer Berg, Berlin. Journal of Sociolinguistics, 2012, Vol. 16, № 1, p. 56-80.

PAREJA-EASTAWAY, M. The effects of the Spanish housing system on the settlement patterns of immigrants. Tijdschrift voor economische en sociale geografie, 2009, Vol. 100, $N^{\circ} 4$, p. 519-534.

PECK, J. Liberating the city: between New York and New Orleans. Urban Geography, 2006, Vol. 27, No 8, p. 681-713.

PENDLEBURY, J.; SHORT, M. \& WHILE, A. Urban World Heritage Sites and the problem of authenticity. Cities, 2009, Vol. 26, No 6, p. 349-358.

PÉREZ-AGOTE, A.; TEJERINA, B. \& BARANANO, M. (editores). Barrios multiculturales. Relaciones interétnicas en los barrios de San Francisco (Bilbao) y Embajadores/Lavapiés (Madrid). Madrid: Trotta, 2010.

PERLMAN, J. Favela. Four decades of living on the edge in Rio de Janeiro. Oxford: Oxford University Press, 2010.

PLAZA, B. The Guggenheim-Bilbao museum effect: a reply to María V. Gomez' "Reflective images: the case of urban regeneration in Glasgow and Bilbao". International Journal of Urban and Regional Research, 1999, Vol. 23, No 3, p. 589-592.

PODAGROSI, A.; VOJNOVIC, I. \& PIGOZZI, B. The diversity of gentrification in Houston's urban renaissance: from cleansing the urban poor to supergentrification. Environment and Planning A, 2011, Vol. 43, N ${ }^{\circ} 8$, p. 1910-1929.

PORTELA, M. Carmo e Santo Antônio além do Carmo: reflexos do processo de revitalização do Centro Histórico de Salvador. Salvador: Tesis de maestría, Universidade Católica do Salvador, 2009.

PORTER, L. \& SHAW, K. (editors). Whose urban renaissance? - An international comparison of urban regeneration policies. London: Routledge, 2008. 
PORTES, A. \& ROBERTS, B. The free market city: Latin American urbanization in the years of the neoliberal experiment. Studies in Comparative International Development, 2005, Vol. 40, № 1, p. 43-82.

PORTES, A.; APARICIO, R.; HALLER, W. \& VICKSTROM, E. Moving ahead in Madrid: aspirations and expectations in the Spanish second generation. International Migration Review, 2010, Vol. 44, No 4, p. 767-801.

PRADO, A. (director). Paraiso for sale - a documentary. Los Angeles: Impacto films, 2012.

PRUIJT, H. The logic of urban squatting. International Journal of Urban and Regional Research, 2012, Vol. 37, No 1, p. 19-45.

PRYTHERCH, D. \& BOIRA, J. City profile: Valencia. Cities, 2009, Vol. 26, No 2, p. 103115.

RAMOS, B.; RODRÍGUEZ, J. y RODRÍGUEZ, O. La investigación social como instrumento en las luchas vecinales. Historia Actual Online, 2008, Vol. 6, № 16, p. 29-39.

RÉRAT, P. \& LEES, L. Spatial capital, gentrification and mobility: evidence from Swiss core cities. Transactions of the Institute of British Geographers, 2011, Vol. 36, № 1, p. 126-142.

RIBERA-FUMAZ, R. Gentrification and retail in Ciutat Vella, Barcelona. In: PORTER, L. \& SHAW, K. (editors). Whose urban renaissance? - An international comparison of urban regeneration policies, London: Routledge, 2008.

RIOL, E. La vivienda de los inmigrantes en Barcelona: el caso del colectivo pakistaní. Scripta Nova. Revista electrónica de Geografía y Ciencias Sociales, 2003, Vol. 8, No 146 (059). Disponible en Internet: http://www. ub.edu/geocrit/sn/sn-146(059).htm

RIVIÈRE, H. Requalificar o século XX: projeto para o centro de São Paulo. In: BIDOU, C.; HIERNAUX, D. \& RIVIÈRE, H. (editores). De volta à cidade: dos processos de gentrificação às políticas de 'revitalização' dos centros urbanos. São Paulo: Annablume, 2006, p. 265-293.
ROBERTS, B. Globalization and Latin American cities. International Journal of Urban and Regional Research, 2005, Vol. 29, No 1, p. 110-123.

ROBINSON, J. Cities in a world of cities: the comparative gesture. International Journal of Urban and Regional Research, 2011, Vol. $35, N^{0} 1$, p. 1-23.

RODRÍGUEZ, A. y VICARIO, L. Innovación, competitividad y regeneración urbana: los espacios retóricos de la "ciudad creativa" en el nuevo Bilbao. Ekonomiaz, 2005, Vol. $58, N^{\circ} 1$, p. 262-295.

RODRÍGUEZ, V.; PUGA, D. y VÁZQUEZ, C. Bases para un estudio de la gentrificación. Boletín de la Real Sociedad Geográfica, 2001, CXXXVII- CSSSVIII, p. 273-310.

ROITMAN, S. \& PHELPS, N. Do gates negate the city? Gated communities' contribution to the urbanization of suburbia in Pilar, Argentina. Urban Studies, 2011, Vol. 48, N ${ }^{\circ}$ 16, p. 3487-3509.

ROLNIK, R. Democracy on the edge: limits and possibilities in the implementation of an urban reform agenda in Brazil. International Journal of Urban and Regional Research, 2011, Vol. 35, № 2, p. 239-255.

ROMERO, L. \& TRUDELLE, C. Megaevents and urban conflicts in Valencia, Spain: contesting the new urban modernity. Urban Studies Research, 2011, Vol. 2011. Disponible en Internet: http://www.hindawi.com/ journals/usr/2011/587523/

ROSE, D.; GERMAIN, A.; BACQUÉ, M.; BRIDGE, G.; FIJALKOW, Y. \& SLATER, T. "Social mix" and neighbourhood revitalization in a transatlantic perspective: comparing local policy discourses and expectations in Paris (France), Bristol (UK) and Montréal (Canada). International Journal of Urban and Regional Research, 2012, Vol. 37, № 2, p. 430-450.

ROUSSEAU, M. Re-imagining the city centre for the middle classes: regeneration, gentrification and symbolic policies in "loser cities". International Journal of Urban and Regional Research, 2009, Vol. 33, No 3, p. 770-788. 
RUBINO, S. A curious blend? City revitalization, gentrification and commodification in Brazil. In: ATKINSON, R. \& BRIDGE, G. (editors). Gentrification in a global context: the new urban colonialism, London: Routledge, 2005, p. 230-244.

SABATINI, F.; SARELLA, M. y VÁSQUEZ, $H$. Gentrificación sin expulsión, o la ciudad latinoamericana en una encrucijada histórica. Revista_180, 2008, №. 24, p. 18-25.

SALCEDO, R. \& TORRES, A. Gated communities in Santiago: wall or frontier? International Journal of Urban and Regional Research, 2004, Vol. 28, No 1, p. 27-44.

SANFELICI, D. Urbanismo neoliberal e gentrificação: as políticas de revitalização do centro de Porto Alegre/RS. Ciências \& Letras, 2007, Vol. 41, No 1, p. 188-203.

SANFELICI, D. O financiero e o imobiliário na reestructuraçao das metrópoles brasileiras. Revista de ANPEGE, 2010, Vol. 6, Nº 1, p. 3-16.

SANTAMARINA, B. Cabanyal, cada vez más cerca. Del lugar al espacio como mercancía. Zainak. Cuadernos de AntropologíaEtnografía, 2009, № 32, p. 915-931.

SARGATAL, M. El estudio de la gentrificación. Biblio 3W. Revista Bibliográfica de Geografía y Ciencias Sociales, 2000, No 228. Disponible en Internet: http://www.ub.es/ geocrit/b3w-228.htm

SARGATAL, M. Gentrificación e inmigración en los centros históricos: el caso del barrio del Raval en Barcelona. Scripta Nova. Revista Electrónica de Geografía y Ciencias Sociales, 2001, Vol. 6, No 94 (66). Disponible en Internet: http://www.ub.es/geocrit/sn-9466.htm

SARGATAL, M. La vivienda en el centro histórico de Barcelona: el caso de la Rambla del Raval. Scripta Nova. Revista Electrónica de Geografía y Ciencias Sociales, 2003, Vol. 8, No 146 (069). Disponible en Internet: http://www.ub.edu/geocrit/sn/sn-146(069). htm
SARGATAL, M. El barrio del Raval de Barcelona (1999-2008). Transformaciones urbanas y nuevos enfoques metodológicos para el estudio del centro historic. Biblio 3W. Revista Bibliográfica de Geografía y Ciencias Sociales, 2009, Vol. 14, No 824. Disponible en Internet: http://www.ub.es/geocrit/b3w-824.htm

SCARPACI, J. Winners and losers in restoring old Havana. In: ASSOCIATION FOR THE STUDY OF THE CUBAN ECONOMY (editor). Cuba in Transition, 2000, Vol. 10. La Habana: Papers and Proceedings of the Tenth Annual Meeting of the Association for the Study of the Cuban Economy, p. 289-300. Disponible en Internet: http://citeseerx.ist. psu.edu/viewdoc/download?doi=10.1.1. $135.3294 \&$ rep $=$ rep $1 \&$ type $=$ pdf

SEQUERA, J. Prácticas distintivas y control urbano como mecanismos de gestión de las conductas. El caso de Lavapiés (Madrid). In: CORNEJO, C.; SÁEZ, J. y PRADA, J. (editores). Ciudad, territorio y paisaje: reflexiones para un debate multidisciplinario. Madrid: CSIC, 2010, p. 119-133.

SHAW, K. Local limits to gentrification: implications for a new urban policy. In: ATKINSON, R. \& BRIDGE, G. (editors). Gentrification in a global context: the new urban colonialism. London: Routledge, 2005, p. 172-188.

SLATER, T. The eviction of critical perspectives from gentrification research. International Journal of Urban and Regional Research, 2006, Vol. 30, No 4, p. 737-757.

SLATER, T. 'A literal necessity to be re-placed': a rejoinder to the gentrification debate. International Journal of Urban and Regional Research, 2008, Vol. 32, No 1, p. 212-223.

SLATER, T. Missing Marcuse: on gentrification and displacement. In: Brenner, N.; Marcuse, P. \& Mayer, M. (editors). Cities for people, not for profit. Critical urban theory and the right to the city. New York: Routledge, 2012, p. 292-311.

SMITH, N. Gentrification and the rent gap. Annals of the Association of American Geographers, 1987, Vol. 77, № 3, p. 462-465. 
SMITH, N. The new urban frontier. Gentrification and the revanchist city. London: Routledge, 1996.

SMITH, N. New globalism, new urbanism: gentrification as global urban strategy. Antipode, 2002, Vol. 34, No 3, p. 427-450.

SMITH, N. On "the eviction of critical perspectives". International Journal of Urban and Regional Research, 2008, Vol. 32, № 1 , p. 195-197.

SOLANA, M. Nuevas dinámicas migratorias en los espacios rurales: vivienda, cambio social y procesos de elitización. El caso del Empordanet (Gerona). Ager. Revista de Estudios sobre Despoblación y Desarrollo Rural, 2006, Vol. 5, p. 57-87.

SOLANA, M. El encanto de lo rural, los términos del debate sobre la migración hacia áreas rurales desde la geografía británica y las contribuciones españolas. Un estado de la cuestión. Biblio 3W. Revista Bibliográfica de Geografía y Ciencias Sociales, 2008, Vol. 13, No. 776. Disponible en Internet: http://www. ub.es/geocrit/b3w-776.htm

SOLANA, M. Rural gentrification in CataIonia, Spain: a case study of migration, social change and conflicts in the Empordanet area. Geoforum, 2010, Vol. 41, p. 508-517.

STEEL, G. \& KLAUFUS, C. Displacement by/for development in two Andean cities. Paper presented at the 2010 Congress of the Latin American Studies Association, Toronto, Canada. Disponible en Internet: http://lasa. international.pitt.edu/members/congresspapers/lasa2010/files/1998.pdf

SUÁREZ, M. La territorialización del arrabal bilbaíno. Nuevas y antiguas formas de uso del espacio público en el barrio de San Francisco. Zainak. Cuadernos de Antropología-Etnografía, 2009, Vol. 32, p. 977-993.

SWANSON, K. Revanchist urbanism heads south: the regulation of indigenous beggars and street vendors in Ecuador. Antipode, 2007 , Vol. $39, \mathrm{~N}^{\circ} 4$, p. 708-728.

SWYNGEDOUW, E.; MOULAERT, F. \& RODRIGUEZ, A. Neoliberal urbanization in
Europe: large-scale urban development and the new urban policy. Antipode, 2002, Vol. $34, N^{\circ} 3$, p. 543-576.

TABAKMAN, E. El Casc Antic de Barcelona. Actuación urbanística o 'limpieza social'? Migración y cambio social. Scripta Nova. Revista Electrónica de Geografía y Ciencias Sociales, 2001, Vol. 6, № 94 (67). Disponible en Internet: http://www.ub.edu/geocrit/sn-94-67.htm

THÖRN, H. In between social engineering and gentrification: urban restructuring, social movements, and the place politics of open space. Journal of Urban Affairs, 2012, Vol. 34, No 2, p. 153-168.

VAINER, C. Pátria, empresa e mercadoria. Notas sobre a estratégia discursiva do Planejamento Estratégico Urbano. In: ARANTES, O.; VAINER, C. \& MARICATO, E. (editors). A cidade do pensamento único. Desmanchando consensus. Petrópolis: Editora Vozes, 2000, p. 75-104.

VAINER, C. Cidade de exceção: reflexões a partir do Rio de Janeiro. Anais do Encontro Nacional da ANPUR, 2011, Vol. 14. Disponible en Internet: http://www.anpur.org.br/ site/anais/ena14/ARQUIVOS/GT1-1019-63320110106150243.pd f

VÁZQUEZ, C. Urban policies and gentrification trends in Madrid's inner city. Netherlands' Journal of Housing and Built Environment, 1992, Vol. 7, № 4, p. 357-376.

VÁZQUEZ, C. Espacio urbano y segregación social. Procesos y políticas en el casco histórico de Madrid. Madrid: Tesis doctoral, Departmento de Geografía Humana, Universidad Autónoma de Madrid, 1996.

VICARIO, L. \& MARTÍNEZ, M. Another 'Guggenheim effect'? The generation of a potentially gentrifiable neighbourhood in Bilbao. Urban Studies, 2003, Vol. 40, № 12, 2383-2400.

VICARIO, L. \& MARTÍNEZ, M. Another "Guggenheim effect"? Central city projects and gentrification in Bilbao. In: ATKINSON, R. \& BRIDGE, G. (editors). Gentrification in a global context: the new urban colonialism. London: Routledge, 2005, p. 155-171. 
VIVES, S. Producing a successful city. Neoliberal urbanism and gentrification in the tourist city. The case of Palma (Majorca). Urban Studies Research, 2011, Vol. 2011. Disponible en Internet: http://www.hindawi. com/journals/usr/2011/989676/.

VISSER, G. \& KOTZE, N. The state and new-build gentrification in central Cape Town, South Africa. Urban Studies, 2008, Vol. $45, N^{\circ} 12$, p. 2565-2593.

WACQUANT, L. Relocating gentrification: the working class, science and the state in recent urban research. International Journal of Urban and Regional Research, 2008, Vol. 32, № 1, p. 198-205.

WALKER, D. Gentrification moves to the global South: an analysis of the Programa de Rescate, a neoliberal urban policy in México City's Centro Histórico. Kentucky: PhD. Thesis, Departament of Geography, University of Kentucky, 2008.

WALLISER, A. \& BRUQUETAS, C. Urban outskirts in Madrid. In: DUBOIS-TAINE, G. (editor). European cities. Insights on outskirts. From Helsinki to Nicosia. Eleven case studies and synthesis. Brussels: European Science Foundation, 2004.

WARD, P. The Latin American inner city: differences of degree or of kind? Environment and Planning A, 1993, Vol. 25, № 8, p. 11311160.

WATT, P. The only class in town? Gentrification and the middle-class colonization of the city and the urban imagination. International Journal of Urban and Regional Research, 2008, Vol. 32, No 1, p. 206-211.

ZIBECHI, R. Territorios en resistencia. Cartografía política de las periferias latinoamericanas. Buenos Aires: Lavaca, 2008.

ZOLINI, G. A inflexão do conceito gentrificação em conjuntos urbanos patrimoniales em ciudades de pequeño porte: os casos mineiros de São Thomé das Letras e Tiradentes. Belo Horizonte: Tesis doctoral, Departmento de Arquitectura, Universidade Federal de Minas Gerais, 2007.

ZUKIN, S. Urban lifestyles: diversity and standardization in spaces of consumption. Urban Studies, 1998, Vol. 35, № 5/6, p. 825839. 